\title{
A new bias-correction method for precipitation over complex terrain suitable for different climate states: a case study using WRF (version 3.8.1)
}

\author{
Patricio Velasquez $^{1,2}$, Martina Messmer ${ }^{1,2,3}$, and Christoph C. Raible ${ }^{1,2}$ \\ ${ }^{1}$ Climate and Environmental Physics Institute, University of Bern, Bern, Switzerland \\ ${ }^{2}$ Oeschger Centre for Climate Change Research, University of Bern, Bern, Switzerland \\ ${ }^{3}$ School of Earth Sciences, University of Melbourne, Melbourne, Victoria, Australia
}

Correspondence: Patricio Velasquez (patricio.velasquez@climate.unibe.ch)

Received: 10 May 2019 - Discussion started: 1 July 2019

Revised: 12 August 2020 - Accepted: 24 August 2020 - Published: 26 October 2020

\begin{abstract}
This work presents a new bias-correction method for precipitation over complex terrain that explicitly considers orographic characteristics. This consideration offers a good alternative to the standard empirical quantile mapping (EQM) method during colder climate states in which the orography strongly deviates from the present-day state, e.g. during glacial conditions such as the Last Glacial Maximum (LGM). Such a method is needed in the event that absolute precipitation fields are used, e.g. as input for glacier modelling or to assess potential human occupation and according migration routes in past climate states. The new bias correction and its performance are presented for Switzerland using regional climate model simulations at $2 \mathrm{~km}$ resolution driven by global climate model outputs obtained under perpetual 1990 and LGM conditions. Comparing the present-day regional climate model simulation with observations, we find a strong seasonality and, especially during colder months, a height dependence of the bias in precipitation. Thus, we suggest a three-step correction method consisting of (i) a separation into different orographic characteristics, (ii) correction of very low intensity precipitation, and (iii) the application of an EQM, which is applied to each month separately. We find that separating the orography into $400 \mathrm{~m}$ height intervals provides the overall most reasonable correction of the biases in precipitation. The new method is able to fully correct the seasonal precipitation bias induced by the global climate model. At the same time, some regional biases remain, in particular positive biases over high elevated areas in winter and negative biases in deep valleys and Ticino in winter and summer.
\end{abstract}

A rigorous temporal and spatial cross-validation with independent data exhibits robust results. The new bias-correction method certainly leaves some drawbacks under present-day conditions. However, the application to the LGM demonstrates that it is a more appropriate correction compared to the standard EQM under highly different climate conditions as the latter imprints present-day orographic features into the LGM climate.

\section{Introduction}

The hydrological cycle is an important component in the Earth's climate system because of its capability to transport and redistribute mass and energy around the world. Changes in the hydrological cycle can lead to droughts or floods and thus impact the ecosystem services. Moreover, it plays an important role in shaping the Earth's climate history (Mayewski et al., 2004). The latter is because the hydrological cycle shows a strong response to different external forcing functions and to changes in atmospheric compositions (Ganopolski and Calov, 2011; Stocker et al., 2013). Namely, hydrology and water resources are strongly influenced by changes in precipitation patterns (Stocker et al., 2013; Raible et al., 2016).

Cold periods, i.e. glacial periods, offer a unique testbed to better understand how the hydrological cycle responds to climate conditions highly different compared to today's climate. The Last Glacial Maximum (LGM) is the most recent 
glacial period and dates back to around $21 \mathrm{ka}$ (Yokoyama et al., 2000; Clark et al., 2009). The LGM is characterised by large ice sheets in the Northern Hemisphere, a global mean temperature roughly 5 to $6.5^{\circ} \mathrm{C}$ colder than today (OttoBliesner et al., 2006), and a global sea level of 115 to $130 \mathrm{~m}$ below the present-day one (Lambeck et al., 2014; Peltier and Fairbanks, 2006). Proxy records for Europe show that the climate was 10 to $14{ }^{\circ} \mathrm{C}$ colder and around $200 \mathrm{~mm} \mathrm{yr}^{-1}$ drier during the LGM compared to recent climate conditions (Wu et al., 2007; Bartlein et al., 2011). These climatic conditions have strong implications not only for nature but also for humans. For instance, Burke et al. (2017) and Wren and Burke (2019) demonstrated the importance of climate conditions and its variability as drivers of human behaviour during the LGM, e.g. the spatial distribution of populations and influence on the cultural and biological evolution (Kaplan et al., 2016). Important modelling tools, e.g. global atmospheric climate models and hydrological models, have been used to describe the Earth's system in the LGM. Compared to the sparse and local climate information from the proxies, these tools provide physically consistent and spatially gridded three-dimensional information on various meteorological variables. Thus, they offer valuable information to improve the understanding of the responses and feedbacks to internal and external forcing on timescales longer than some centuries (e.g. Xu, 2000; Andréasson et al., 2004; Xu et al., 2005; Fowler et al., 2007a; Yang et al., 2010; Chen et al., 2012). Global climate models are generally in line with the proxy evidence and depict a European climate that was largely colder and drier than today. However, they underestimate the amplitudes of the changes compared to proxy evidence and poorly represent areas with complex terrain (e.g. Hofer et al., 2012a; Ludwig et al., 2016).

The modelling tools also show other uncertainties, in particular in the hydrological cycle, as not all relevant processes are explicitly simulated by the models (e.g. Ban et al., 2014; Giorgi et al., 2016). This is especially true for global models, which have a comparably coarse spatial resolution. Hence, most processes governing regional- to local-scale precipitation are not resolved and need to be parameterised (Leung et al., 2003; Su et al., 2012), resulting in a strong parameter dependence when simulating regional-scale precipitation (Rougier et al., 2009). To overcome some of the uncertainties, regional climate models (RCMs) are used to dynamically downscale global climate models. Many RCM simulations are carried out within the framework of the Coordinated Regional Downscaling Experiment (CORDEX), which defines one of the premier goals to better understand relevant phenomena at finer scales (Moss et al., 2010). Even though regional climate models can solve atmospheric equations on a much finer scale than global models, the simulated precipitation patterns still show large biases for present-day climate when comparing them to observations. This has, for example, been illustrated by the CORDEX simulations analysed by Casanueva et al. (2016) and Rajczak and Schär (2017). Not only are these biases produced by initial and boundary conditions provided by global climate models (GCMs), but they are also related to regions characterised by complex topography and to processes that correspond to a finer scale, such as cloud microphysical processes. These processes need to be parameterised as they cannot be explicitly resolved because of the RCM resolution used in CORDEX (Boer, 1993; Zhang and McFarlane, 1995; Fu, 1996; Haslinger et al., 2013; Yang et al., 2013; Warrach-Sagi et al., 2013; Maraun and Widmann, 2015; Hui et al., 2016). To overcome these shortcomings, RCMs need to be run at a resolution where they can explicitly resolve some of the relevant processes, such as convection (e.g. Giorgi et al., 2016; Messmer et al., 2017). Even though the convection-resolving RCMs can describe precipitation much more precisely, biases are still evident (e.g. Ban et al., 2014; Gómez-Navarro et al., 2018). These inconsistencies and uncertainties may, for example, impact the results obtained through hydrological and glacier modelling that follow next in the modelling chain (Allen and Ingram, 2002; Seguinot et al., 2014; Felder et al., 2018).

Some climate change studies try to correct parts of these errors in precipitation patterns and intensities by so-called bias-correction methods (Maraun et al., 2010). These biascorrection methods are needed in the event that absolute values matter, e.g. for the forcing of impact models like glaciers or ice sheets (Jouvet et al., 2017; Jouvet and Huss, 2019), when temperature thresholds are important as limiting factor, e.g. for vegetation coverage, freezing of water, snowfall vs. rainfall, or when precipitation thresholds are essential (Liu et al., 2006; Zhao et al., 2017; Liu et al., 2018; Chen et al., 2019; Wang et al., 2020). So far, several correction methods have been suggested in the literature, e.g. linear scaling, local intensity scaling, or power transformation (e.g. Berg et al., 2012; Fang et al., 2015; Lafon et al., 2013). An overview of different methods and their limitations is given in Maraun (2016) and Maraun and Widmann (2018b). Another important bias-correction method is the empirical quantile mapping (EQM), which is known as one of the best techniques to correct precipitation biases in the present-day climate (e.g. Lafon et al., 2013; Teutschbein and Seibert, 2012, 2013; Teng et al., 2015). If the method is applied to a climate state different from the present one, all these methods suffer basically from the assumption of stationarity in the biases, since they are trained with a climate that does not correspond to the simulated climate that is afterwards bias corrected. Statistical relationships between observations and model output are used to estimate transfer functions in the observed period and are then applied to different climate states, e.g. past and future climate change scenarios. These statistical relationships and the bias structure can be altered by changes in the precipitation processes in the different climate states. Focusing on the LGM climate, an important process is related to changes in the albedo due to differences in vegetation and land cover (Kaplan et al., 2016; Velasquez et al., 2020). Also, changes in near-surface condensation processes may play an important 
role, i.e. freezing of near-surface moisture over areas covered by ice. These processes can influence the temperature and moisture profiles and thus also precipitation processes. Other important processes are linked to modifications in the general atmospheric circulation and in the water availability (Hofer et al., 2012b; Kageyama et al., 2020; Pinto and Ludwig, 2020). This can also regulate the water transport and thus also the precipitation patterns.

Hence, these changes amongst others may violate the stationarity assumption of bias-correction methods. Besides the assumption of stationarity of the transfer functions, these correction methods only implicitly consider orographic features that strongly affect precipitation and its biases (e.g. Piani et al., 2010b; Amengual et al., 2011; Berg et al., 2012; Chen et al., 2013; Cannon et al., 2015; Fang et al., 2015). Note that this implicit consideration relies on the orography where the method is trained. Hence, the applicability of bias corrections may not be justified to different climate states where the topography strongly changes, such as in the LGM.

This calls for a flexible method that can ameliorate the assumption of stationarity in the biases when correcting precipitation errors. One possibility is to apply a cluster analysis to precipitation and its biases to identify classes with similar bias behaviour. An example for Switzerland of such an approach is presented by Gómez-Navarro et al. (2018). The drawback of such an approach for our purpose is that the cluster analysis still relies on the characteristics and circulation of the current climate. To be as independent from current climates as possible and to provide a correction that includes important characteristics of the Alpine climate, we came up with "static" characteristics, i.e. topography height and slope orientation, and the assumption that relationships to these static characteristics remain unchanged in different climate states. Thus, our work aims at presenting a new biascorrection method that fills this gap by using orographic features as variables for the correction. Such a correction avoids the explicit usage of current atmospheric circulation and provides a new alternative to the standard EQM for areas with complex topography during highly different climate states, i.e. glacial times.

The new method is based on EQM (Lafon et al., 2013; Teutschbein and Seibert, 2012, 2013; Teng et al., 2015) explicitly combined with orographic characteristics and attempts to correct wet or dry biases that are introduced by parameterisations and numerical formulations in global, regional, or a combination of both models. Such biases include especially those that are associated with orographic effects, namely, vertical motion leading to precipitation. Observations or proxy reconstructions are limited over the Alps during glacial times. Thus, the method is directly evaluated under present-day climate conditions and its performance compared to the standard EQM is assessed in an LGM climate simulation. The data to be corrected stem from climate simulation performed with the high-resolution Weather Research and Forecasting (WRF) RCM (Skamarock and
Klemp, 2008) driven by simulations under perpetual climate conditions using the Community Climate System Model version 4 (CCSM4; Gent et al., 2011). To estimate the transfer functions of the EQM we use two observation data sets separately: one for Switzerland (MeteoSwiss, 2013) and one for the Alpine region (Isotta et al., 2014). The focus of the presented study is on the method itself and its evaluation. The latter consists of assessing the performance over the Alps, the temporal and spatial transferability, and the comparison of the new method and standard EQM method (Lafon et al., 2013) under LGM conditions.

The paper is structured as follows. Section 2 describes the models and data sets used to construct the method. Section 3 presents the new bias-correction method. Section 4 evaluates the new method. Finally, a summary and conclusive remarks are given in Sect. 5.

\section{Models and data}

We use a present-day and an LGM simulation to create and evaluate the new bias correction. Thereby, we employ a model chain that consists of a global climate model and a regional climate model, where the global climate model provides the boundary conditions for the regional climate model.

The global climate model is the Community Climate System Model (version 4; CCSM4; Gent et al., 2011). The model's atmospheric component is calculated by the Community Atmosphere Model version 4 (CAM4; Neale et al., 2010) and the land component by the Community Land Model version 4 (CLM4; Oleson et al., 2010). Only two components, the so-called data models, are used for the ocean and sea ice; i.e. the atmospheric component is forced by timevarying sea surface temperatures and sea ice cover obtained from a coarser-resolved fully coupled $1990 \mathrm{AD}$ and LGM simulation with CCSM3, respectively (Hofer et al., 2012a). The atmosphere land-only model was run with a horizontal resolution of $1.25^{\circ} \times 0.9^{\circ}$ (longitude $\times$ latitude) and with 26 vertical hybrid sigma-pressure levels. Two global climate simulations are performed each covering 31 years: (i) under perpetual $1990 \mathrm{AD}$ and (ii) under LGM conditions, respectively. The orbital forcing and atmospheric composition are adjusted to the respective period (Table 1). The temporal resolution of the output is 6-hourly. More detailed information on these simulations and their settings is presented in Hofer et al. (2012a, b) and Merz et al. (2013); Merz et al. (2014a, b); Merz et al. (2015).

To investigate the climate over central Europe and in particular over Switzerland in more detail, an RCM is used for the dynamical downscaling. Note that Switzerland is only covered by 12 grid points and the Alps are represented with a maximum height of approximately $1400 \mathrm{~m}$ a.s.l. in CCSM4. We use WRF model version 3.8.1 for the dynamical downscaling (Skamarock and Klemp, 2008). The model is set up with four two-way nested domains with a nest ratio of $1: 3$. 
Table 1. External forcing used in Hofer et al. (2012a, b) for 1990 AD and LGM conditions.

\begin{tabular}{lrr}
\hline Parameter name & $1990 \mathrm{AD}$ & $\mathrm{LGM}$ \\
\hline $\mathrm{TSI}\left(\mathrm{W} \mathrm{m}^{-2}\right)$ & 1361.77 & 1360.89 \\
Eccentricity $\left(10^{-2}\right)$ & 1.6708 & 1.8994 \\
Obliquity $\left(^{\circ}\right)$ & 23.441 & 22.949 \\
Angular precession $\left(^{\circ}\right)$ & 102.72 & 114.43 \\
$\mathrm{CO}_{2}(\mathrm{ppm})$ & 353.9 & 185 \\
$\mathrm{CH}_{4}(\mathrm{ppb})$ & 1693.6 & 350 \\
$\mathrm{~N}_{2} \mathrm{O}(\mathrm{ppb})$ & 310.1 & 200 \\
\hline
\end{tabular}

The domains have horizontal resolutions of $56,18,6$, and $2 \mathrm{~km}$, respectively, and 40 vertical eta levels. The outermost domain includes an extended westward and northward area that takes the Alpine region as the midpoint (Fig. 1). Moreover, the innermost domain focuses on the Alpine region. The fine resolution of $2 \mathrm{~km}$ over this area is important as it covers a highly complex terrain. The resolution in the two innermost domains permits the explicit resolution of convective processes. Thus, no parameterisation for convection is used in these two domains and precipitation is described by microphysical processes (Table 2). Convection-permitting model resolutions are in general preferred as many recent studies show better performance in simulating precipitation (e.g. Ban et al., 2014; Prein et al., 2015; Kendon et al., 2017; Berthou et al., 2018; Finney et al., 2019). However, we shall keep in mind that some biases in temperature and cloud formation may be produced by this setup, which may lead to additional biases in precipitation as shown in Ban et al. (2014). Table 2 lists the relevant parameterisation schemes chosen to run WRF with.

WRF is driven by, but not nudged to, the corresponding global simulation and is run for 30 years using perpetual 1990 AD and LGM conditions, respectively (Table 1). For the LGM simulation, the surface conditions need some further adjustments. These include the lowering of the sea level and extended ice sheets as specified in the PMIP3 protocol (Fig. 3; for more details, see Ludwig et al., 2017). The glaciation over the Alpine region (obtained from Seguinot et al., 2018) and other glaciated areas (e.g. Pyrenees, from Ehlers et al., 2011) are modified according to LGM conditions (Fig. 3b). Additionally, the land cover and land use are altered to comply with LGM conditions, as described in Velasquez et al. (2020). Each 30-year simulation is split up into 10 individual 3-year simulations and carried out with adaptive time step in order to increase the throughput on the available computer facilities. For each of the 3 -year simulations, a 2-month spin-up time is considered to account for the longer equilibrium times of the land surface scheme of WRF. Tests show that the WRF land scheme reaches a quasi-equilibrium after approximately $15 \mathrm{~d}$.
Two gridded observational data sets for daily precipitation are used: RhiresD (MeteoSwiss, 2013) and the Alpine Precipitation Grid Dataset (APGD; Isotta et al., 2014). Both data sets cover more than 35 years. In this study, we use only the 30-year period (1979-2008). Note that we carry out a bilinear interpolation using the Climate Data Operators (CDO; Schulzweida, 2019) to convert both observational data sets into the corresponding grid of WRF. The RhiresD has a spatial resolution of approximately $2 \times 2 \mathrm{~km}$ and covers only Switzerland (MeteoSwiss, 2013). This data set is based on rain gauge measurements distributed across Switzerland (for more details, see Isotta et al., 2014; Güttler et al., 2015). These point measurements are spatially interpolated to obtain a gridded data set, which is described in more detail in Frei and Schär (1998), Shepard (1984) and Schwarb et al. (2001). The APGD encompasses the entire Alpine region with a spatial resolution of $5 \times 5 \mathrm{~km}$ (Isotta et al., 2014). It was developed in the framework of EURO4M (European Reanalysis and Observations for Monitoring) by using a distanceangular weighting scheme that integrates climatological precipitation using the local orography and the rain gauge measurements (Isotta et al., 2014). For our analysis, the Alpine areas of Italy and Slovenia are excluded from APGD because of their poor station density covering the period 1979-2008 compared to RhiresD, especially over complex topography and at high altitudes. Note that all data sets consider daily precipitation as total precipitation, i.e. both solid and liquid precipitation, and convective and non-convective precipitation. Moreover, days without precipitation are treated as censored values, i.e. not considered in the analysis, when daily precipitation is equal to $0 \mathrm{~mm}$, although in the case of observations this is equivalent to $0.1 \mathrm{~mm} \mathrm{~d}^{-1}$ due to gauge precision.

The observational gridded data sets provide valuable insights. However, they also contain some discrepancies and uncertainties due to interpolation and extrapolation methods; e.g. high precipitation intensities are systematically underestimated and low intensities overestimated, especially in areas where observations are not available, i.e. on high elevated areas, such as mountain peaks. The magnitude of these errors depends on the season and the altitude. In regions above $1500 \mathrm{~m}$ a.s.l., the error can be higher than $30 \%$ because of a "gauge undercatch" induced by strong winds and the applied interpolation method carried out with a distanceangular weighting scheme (Frei and Schär, 1998; Nešpor and Sevruk, 1999; Auer et al., 2001; Ungersböck et al., 2001; Schmidli et al., 2002; Frei et al., 2003; MeteoSwiss, 2013; Isotta et al., 2014). Note that the limitations of the observational data sets are not included in the analysis of this study; i.e. we consider the observational gridded data sets as truth. Nevertheless, one shall keep the limitations of the observational data in mind, in particular when discussing the remaining biases in areas and seasons where the observational data sets also have problems. 


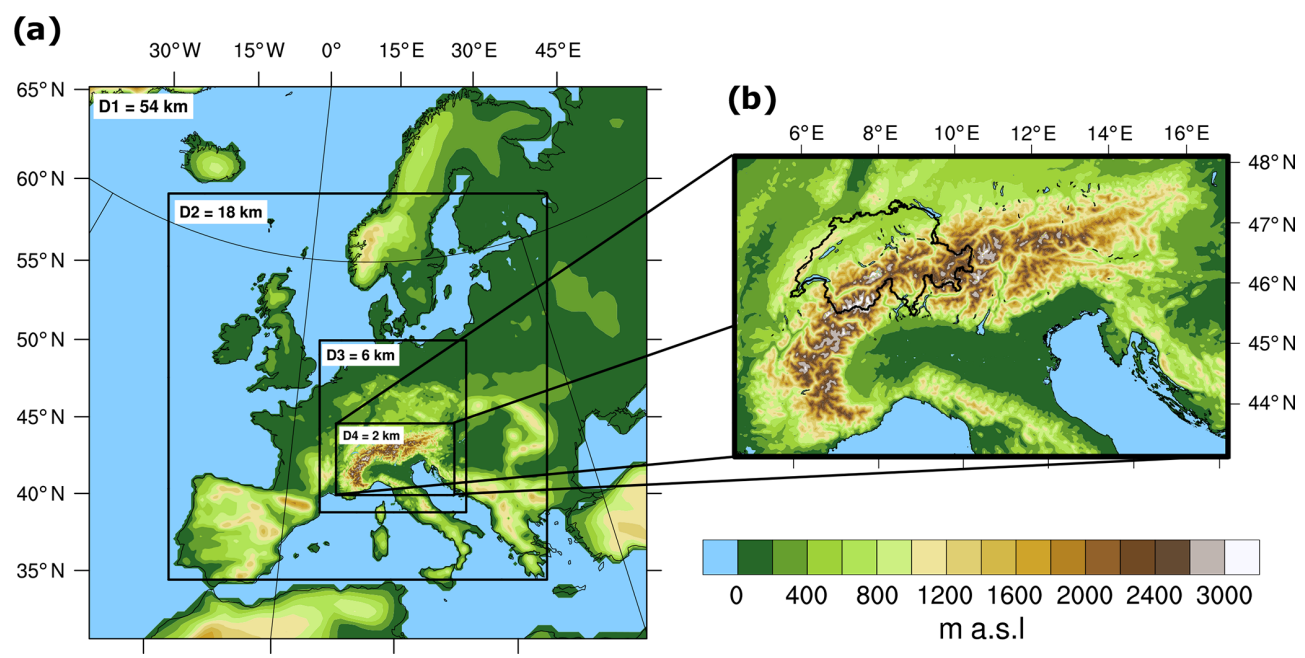

Figure 1. WRF domains and present-day topography. Panel (a) illustrates the present-day topography and the four domains used by WRF. Panel (b) shows the fourth domain including the area of interest (Switzerland) outlined by a black line.

Table 2. Important parameterisations used to run WRF.

\begin{tabular}{llll}
\hline Parameterisation & Parameter name & Chosen parameterisation & Applied to \\
\hline Microphysics & mp_physics & WRF single-moment six-class scheme & Domains 1-4 \\
Longwave radiation & ra_lw_physics & RRTM scheme & Domains 1-4 \\
Shortwave radiation & ra_sw_physics & Dudhia scheme & Domains 1-4 \\
Surface layer & sf_sfclay_physics & MM5 similarity & Domains 1-4 \\
Land-water surface & sf_surface_physics & Noah - multi-parameterisation land surface model & Domains 1-4 \\
Planetary boundary layer & bl_pbl_physics & Yonsei University scheme & Domains 1-4 \\
Cumulus & cu_physics & Kain-Fritsch scheme & Domains 1-2 \\
& & No parameterisation & Domains 3-4 \\
\hline
\end{tabular}

\section{Bias correction}

The correction method, developed in this study, consists of three steps: (i) separation with respect to different orographic characteristics, (ii) adjustment of daily precipitation with very low intensity, and (iii) application of the EQM. Each of these three steps is described in more detail in the following paragraphs.

In a first step, three orographic characteristics are used to separate the region of interest into several groups. These characteristics are height, slope orientations, and a combination of both. The height ranges from approximately $200 \mathrm{~m}$ a.s.l. to a maximal value of $3800 \mathrm{~m}$ a.s.l. over the area of interest. Thus, the groups are selected by height intervals, which cover the range from 400 to $3200 \mathrm{~m}$ a.s.l. Two height intervals are tested separately: 100 and $400 \mathrm{~m}$ (e.g. height intervals of $400 \mathrm{~m}$ are shown in Fig. 2). The heights below 400 and above $3200 \mathrm{~m}$ a.s.l. are considered as two additional height intervals. The second characteristic, used to group the region of interest, is four slope orientations: north $\left(315^{\circ} \leq\right.$ slope orientation $\left.<45^{\circ}\right)$, east $\left(45^{\circ} \leq\right.$ slope orientation $\left.<135^{\circ}\right)$, south $\left(135^{\circ} \leq\right.$ slope orientation $\left.<225^{\circ}\right)$ and west $\left(225^{\circ} \leq\right.$ slope orientations $\left.<315^{\circ}\right)$. Note that this characteristic is obtained by summing the two slope vectors that are directly provided by the RCM. Combining both characteristics, the groups are selected by height intervals and then separated into subgroups by the slope orientations.

In a second step, we correct the daily simulated precipitation with very low intensity in each group (or subgroup) and each month of the year separately. The reason for this is that the frequency of precipitation with very low intensity is often strongly overestimated due to the drizzle effect produced by the RCM (Murphy, 1999; Fowler et al., 2007b; Maraun et al., 2010).This overestimation can distort the precipitation distribution substantially, i.e. shifting the quantiles, producing inappropriate corrections in the third step when EQM is applied (Teutschbein and Seibert, 2012; Lafon et al., 2013).

To correct precipitation with very low intensity, simulated precipitation values are censored by setting them to zero when they are below a specific threshold. Many studies use a static threshold for the entire simulated data set which is between 0.01 and $1 \mathrm{~mm} \mathrm{~d}^{-1}$ (Piani et al., 2010a; Lafon et al., 2013; Maraun, 2013). To be consistent with the different biases' treatment across the groups, we calculate a static 


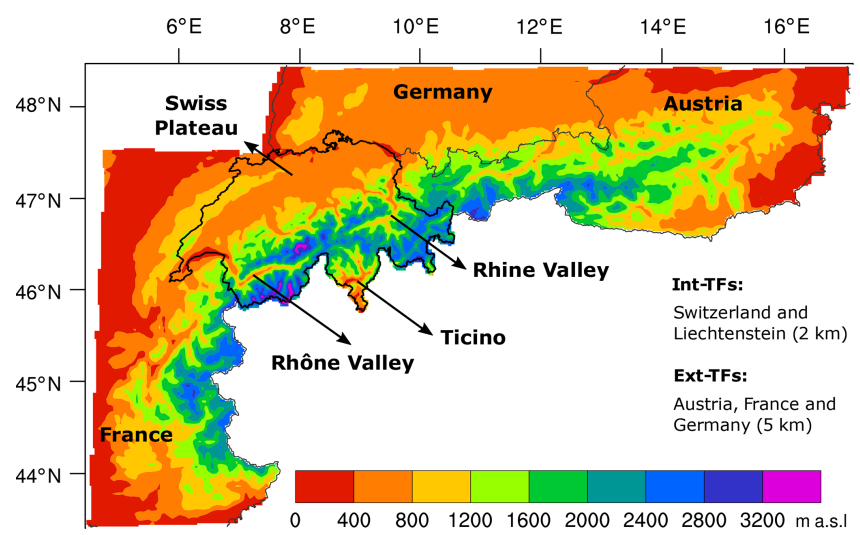

Figure 2. WRF innermost domain indicates the present-day height classes used for the correction method ( $400 \mathrm{~m}$ interval) for the IntTFs at $2 \mathrm{~km}$ resolution (Switzerland, black outline) and for the ExtTFs at $5 \mathrm{~km}$ resolution (other shaded areas). Additionally, some labels are added to identify some specific areas in Switzerland that are used throughout the paper.

threshold for each group (or subgroup) and each month of the year. Thus, we carry out the first part of the local intensity scaling method (Schmidli et al., 2006; Teutschbein and Seibert, 2012) before applying the quantile mapping technique. This method consists of choosing the threshold in a way such that the number of days with precipitation in the simulation coincides with the precipitation-day occurrence from the observations. In our work, the threshold can vary from group to group and from month to month between 0.001 and $1 \mathrm{~mm} \mathrm{~d}^{-1}$.

In a third step, we correct the daily precipitation rate using an EQM method (Themessl et al., 2011; Lafon et al., 2013; Fang et al., 2015; Teng et al., 2015). Note that censored values are excluded from this step. EQM is based on the assumption that all probability distribution functions are unknown, i.e. non-parametric (Wilks, 2011). The method consists of adjusting the quantile values from a simulation $\left(Q_{\text {sim }}\right)$ to those from the observations ( $\left.Q_{\text {obs }}\right)$ through a transfer function (TF; Fig. 4). The method is implemented by splitting each cumulative distribution function, i.e. observed and modelled, into 100 discrete quantiles. For each quantile value, the adjustment is carried out with a linear correction (Lafon et al., 2013), where $Q_{\text {sim }}$ is transformed into $Q_{\text {sim }}{ }^{*}$ (corrected quantile; Eq. 1).

$Q_{\text {sim }}{ }^{*}=\mathrm{TF} \times Q_{\text {sim }}$, where $\mathrm{TF}=\frac{Q_{\text {obs }}}{Q_{\text {sim }}}$

This linear correction is akin to the factor of change or delta change used in Hay et al. (2000). For values that are between quantiles, the same linear correction is used, but the $\mathrm{TF}$ is approximated by using a linear interpolation between the TFs related to the two nearest quantiles. In cases where values are below (above) the first (last) quantile, the TF related to the first (last) quantile is used for the adjustment.
Similar methods were successfully applied to correct biases in precipitation simulated by RCMs (e.g. Sun et al., 2011; Themessl et al., 2012; Rajczak et al., 2016; Gómez-Navarro et al., 2018).

To combine all steps, the first part of the local intensity scaling method and the EQM are applied to each (sub)group defined in the first step and to each month of the year, separately, by pooling all grid points that belong to each group and handling them as a single distribution of daily precipitation. This results in a set of TFs for each (sub)group and each month of the year. For instance, it results in nine TFs for each month and in total 108 TFs throughout the year when the correction is carried out using height classes of $400 \mathrm{~m}$. Moreover, the correction is afterwards applied to the daily precipitation at every grid point using the TFs that are common to all elements within the same group (or subgroup) and month. Thus, the new correction method guarantees that seasonality and height are taken into account.

To come up with a final method for the Alpine region, we first evaluate the influence of the different orographic characteristics (step 1). To be consistent with former studies (e.g. Sun et al., 2011; Themessl et al., 2012; Wilcke et al., 2013; Rajczak et al., 2016), the evaluation uses the same region where the TFs are estimated. This means that the Swiss region in the WRF output (at $2 \mathrm{~km}$ resolution) is defined as the area to be corrected and RhiresD (at $2 \mathrm{~km}$ resolution) is used to obtain the TFs and to evaluate the different correction methods. These TFs are called internal TFs (Int-TFs) during the cross-validation process later on.

Once the final method is determined, we apply two crossvalidations to test the method more rigorously, as suggested by Bennett et al. (2014). First, a temporal cross-validation is applied. Thereby, the 30-year period is split into a 15 -year training period and an independent 15 -year verification period. New sets of TFs are calculated from the first and last 15 years of the 30-year period, separately. Each set of TFs is then applied to the first and last 15 years, which results in four newly corrected precipitation data sets, namely, two dependent and two independent ones. Second, we apply a spatial cross-validation. Thereby, Switzerland is defined as the area to be corrected (WRF output at $2 \mathrm{~km}$ resolution). For the spatial cross-validation, an additional set of TFs is then estimated from the corresponding Alpine region of Germany, France, and Austria excluding Switzerland (called the external TFs; Ext-TFs) using APGD (at $5 \mathrm{~km}$ resolution; Fig. 1c). Ext-TFs are carried out at $5 \mathrm{~km}$ horizontal resolution and applied to Switzerland at $2 \mathrm{~km}$ resolution. This guarantees that no additional uncertainty is introduced by a spatial interpolation when comparing the results of Ext-TF and Int-TF. To see that the coarser resolution of APGD has no influence on the result, the performance of the correction method is also evaluated when using Ext-TFs trained at $5 \mathrm{~km}$ and then applied to the Swiss region at $5 \mathrm{~km}$ resolution. Note that these results only show small differences to the $2 \mathrm{~km}$ results and are therefore not shown. To determine the improvement of 

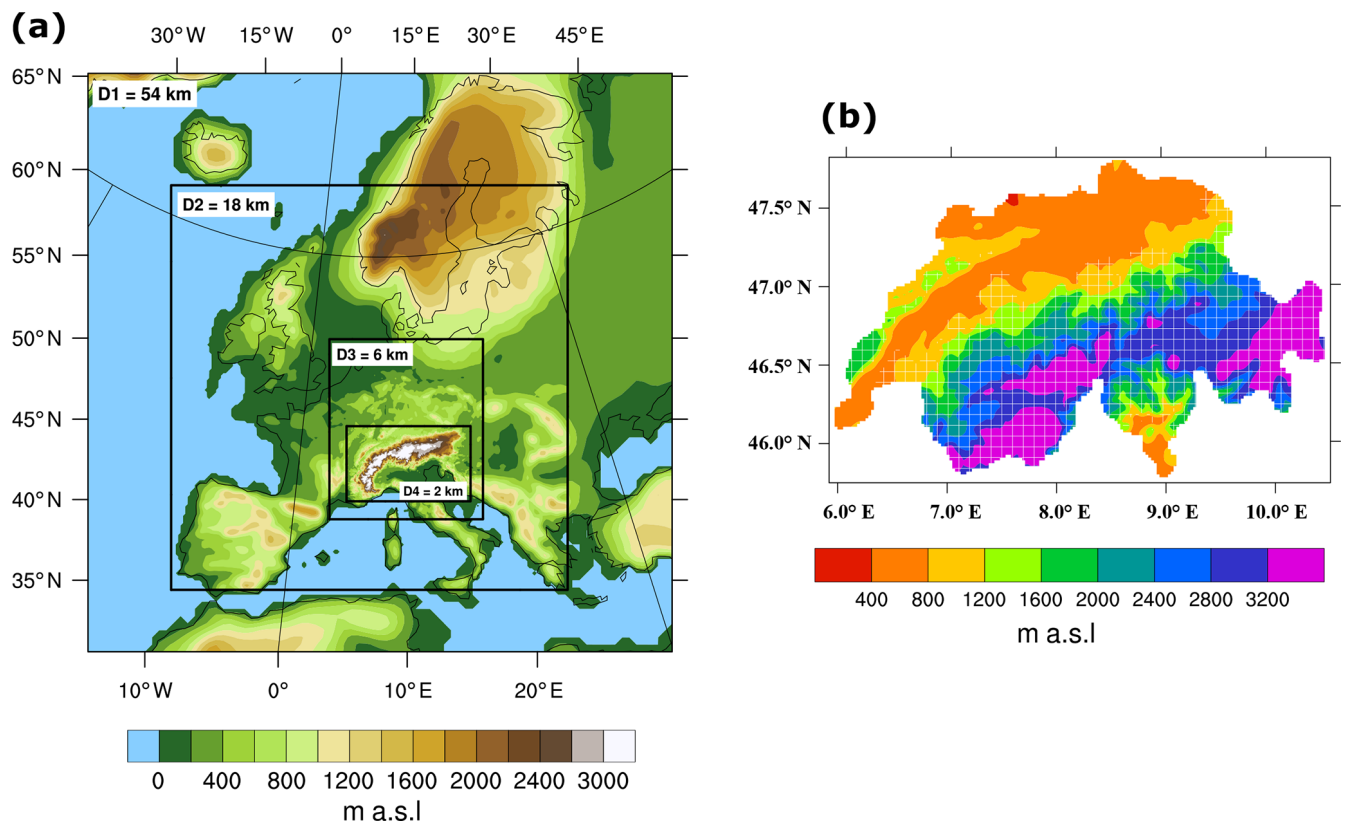

Figure 3. WRF domains and LGM topography. Panel (a) illustrates the LGM topography, LGM sea level, and the four domains used by WRF. Panel (b) indicates the height classes for the correction method (400 m interval) using the LGM topography over Switzerland at $2 \mathrm{~km}$ resolution; crosshatched areas are covered by glaciers.

\section{Cumulative density function}

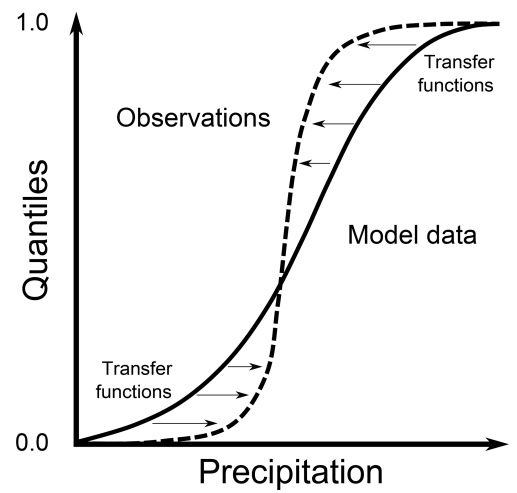

Figure 4. Diagram of the EQM technique. The solid (dashed) line shows a schematic simulated (observed) cumulative distribution.

the new method, we compare it to a simple method that is carried out without orographic features using one EQM for the entire region in each month (12 EQM in total, referred to as one EQM-TF hereinafter).

\section{Validation of the method}

\subsection{Biases of WRF and their seasonality}

To obtain insights into the performance of the RCM over complex topography, we compare the spatial and temporal representation of the simulated precipitation (the raw model output) with RhiresD. Focusing on monthly mean precipitation intensity across Switzerland, the box plots illustrate biases in the climatological annual mean cycle (Fig. 5a). The climatological mean values are slightly overestimated during colder months, i.e. between November and March, and are underestimated during warmer months, i.e. between April and October but especially in September. In addition to the climatological mean values, Fig. 5a also shows the distributions of monthly mean precipitation intensity and their interquartile ranges. In colder months, the simulated distributions are wider and shifted to higher values than the observed distributions, whereas a clear shift to less precipitation is found compared to the observed ones during warmer months. Overall, the interquartile ranges are reasonably simulated, which means that WRF realistically represents the variability of monthly mean precipitation intensity. Extreme precipitation, however, is strongly underestimated.

The annual cycle and the distributions of monthly mean precipitation intensities are estimated for different height classes to get additional understanding of the behaviour of the simulated precipitation and also to explicitly illustrate the relation of the precipitation biases to the topography. This is summarised in Fig. 5b and c for the height classes of $400-800$ and $2800-3200 \mathrm{~m}$ which mostly represent the low and high altitudes, respectively. The climatological monthly means of the colder months, i.e. from November to March, are generally underestimated in the lower height classes but overestimated at high altitudes. Additionally, we assess the 

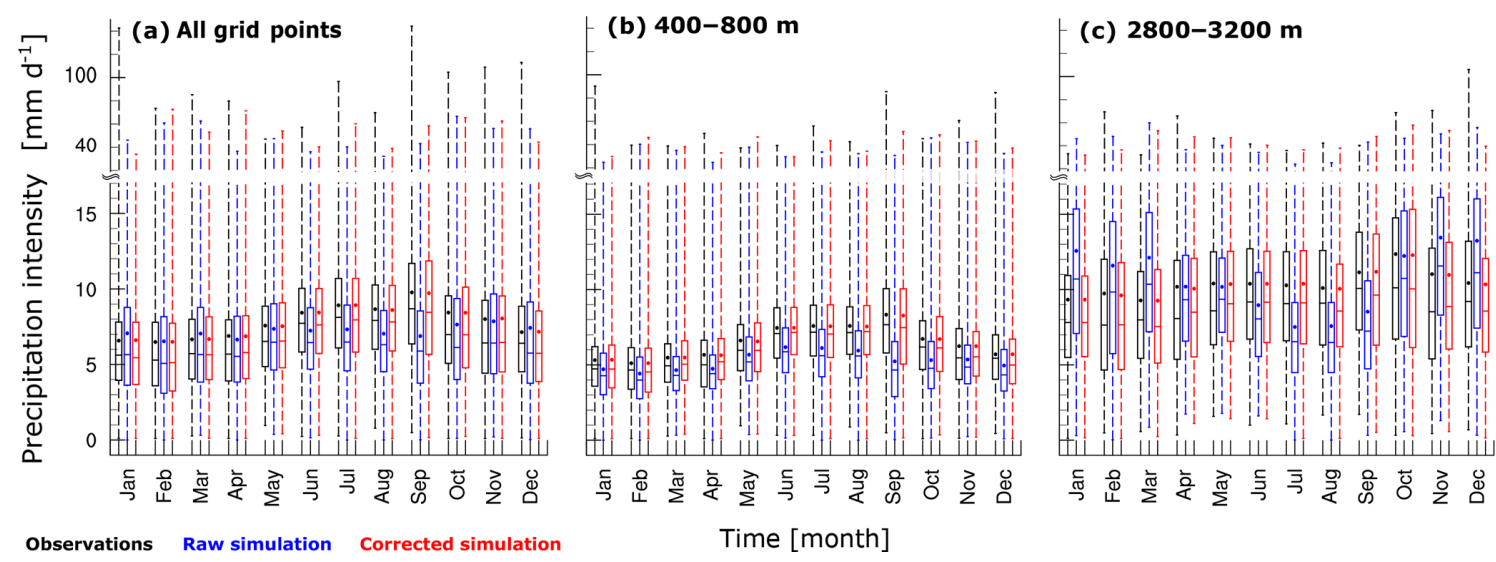

Figure 5. Boxplots illustrate the spatial distribution of monthly mean values of precipitation intensity across a specific area within 30 years: (a) the area covers all grid points over entire Switzerland, (b) the grid points in the height class of 400-800 m, and (c) the grid points in the height class of 2800-3200 m. Black box plots represent the observations (RhiresD); blue and red ones the raw and corrected simulations, respectively. Top and bottom ends of the dashed lines represent the maximum and minimum values, respectively. Dots represent the spatial climatological mean value.

biases at each grid point in a scatter plot. To that end, we select two months that mainly represent colder and warmer months, namely, January and July, respectively. We find a clear positive correlation between the biases and altitudes in January (Fig. 6a). In warmer months, i.e. April to October, both height classes (400-800 and 2800-3200 m) reveal an underestimation in the climatological monthly means compared to the observations. This is again confirmed by scatter plots between biases at grid points and altitude, where only a mean shift is found in July (Fig. 6b). Overall, the simulated annual cycle changes from a weak cycle at low altitudes, in agreement with the one of the observations, to a strong and inverse seasonal cycle at high altitudes (Fig. $5 \mathrm{~b}$ and c). An inverse annual cycle is also identified by Gómez-Navarro et al. (2018), who used a similar model chain compared to the one in this study. These authors found that the inversed annual cycle in precipitation is caused by the driving global climate model. Furthermore, we observe positive biases in the interquartile ranges during colder months and a slight underestimation during warmer months (Fig. $5 \mathrm{~b}$ and c). So far, the analysis of the biases suggests that including the height dependence can help in improving correction methods.

To better describe the spatial biases related to colder and warmer months, we select two months that mainly represent each period, namely, January and July. For these example months, we present the spatial patterns of the biases in the monthly mean precipitation intensity, in the variability illustrated by the interquartile range, and in the wet-day frequency. Note that the observational data sets are generally considered reliable and represent orographic features well, although at high altitudes fewer observations are available (Isotta et al., 2014). Furthermore, these spatial patterns implicitly illustrate the relation between the precipitation biases and the topography considering an uncertainty of around
$30 \%$ acceptable in the simulated precipitation due to the uncertainty in the observational data sets (Sect. 2).

The biases in the climatological mean precipitation intensity at each grid point (Fig. 7a and d) confirm the height dependence and seasonality already shown in Fig. 5. The strongest positive biases are mainly observed over mountains and during colder months, whereas the Swiss Plateau seems to be reasonably well simulated (Fig. 7a). Note that also the observations tend to underestimate precipitation in mountain regions, so that a part of the strong positive bias is related to observational uncertainties (Isotta et al., 2014). In warmer months, the strongest negative biases are found in the northwestern part of Switzerland, Ticino, and in the steep valleys, where the Rhône Valley is marked by the strongest biases. In high mountain regions, smaller positive biases are identified during warmer months than during colder months (Fig. 7d). The strongest biases over mountains and in steep valleys seem to be induced by an amplification of different observed precipitation climatologies that govern those areas; namely, the mountains are known as wet regions and the steep valleys as dry areas (for more details, see Frei and Schär, 1998; Schwarb et al., 2001). This gives a first hint that different processes may lead to the biases. The positive precipitation bias over mountains in colder months may be mainly related to wet bias of the global simulation and synoptic transport, which is also overestimated in the global simulation (Hofer et al., 2012a, b). The resolution of the RCM seems to be important as this affects the representation of steep valleys, especially during convective processes in warmer months. The same is also true for colder months but to a lesser extent, as convective processes only play a minor role in these months.

The interquartile ranges of the distribution of monthly mean precipitation intensity at each grid point (Fig. 8a and d) are strongly overestimated over the Alps during colder 

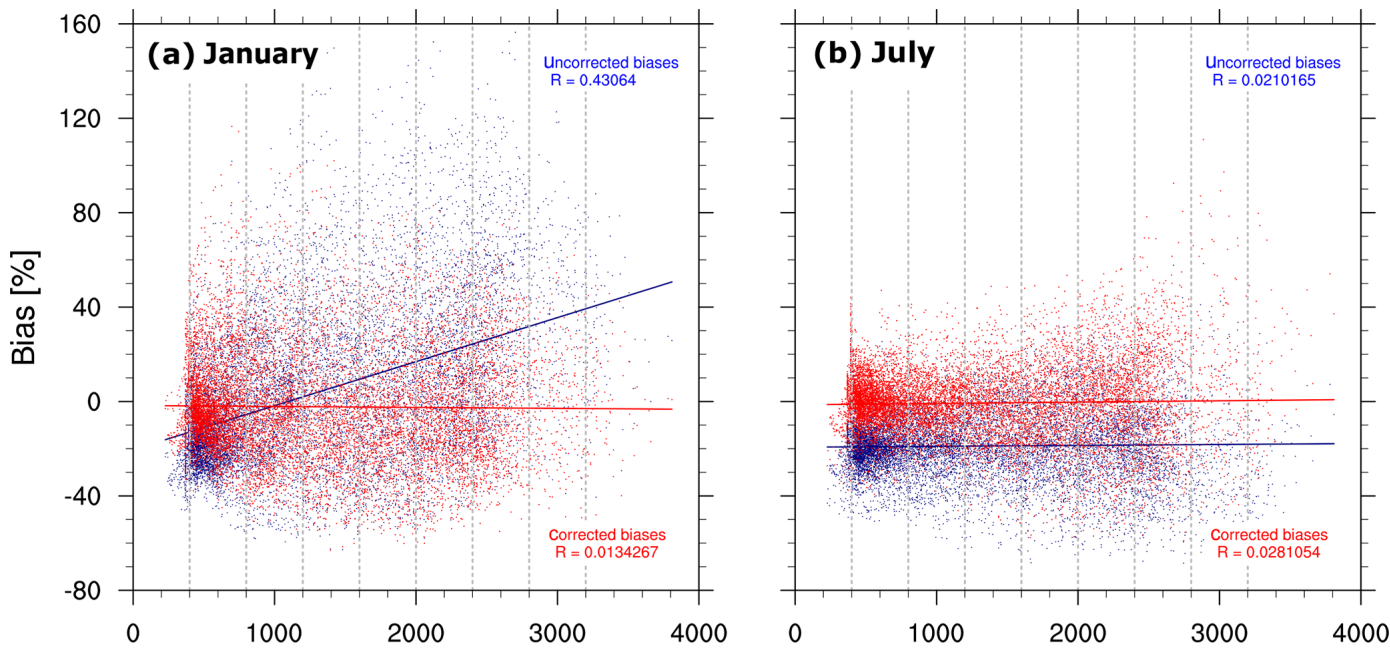

Height $[\mathrm{m}]$

Figure 6. Biases over Switzerland. Blue (red) indicates the original (corrected) biases. Panel (a) illustrates the bias versus height at each grid point during January; panel (b) is the same as (a) but for July. Solid lines represent the linear regressions, $R$ the correlation between biases and height, and vertical dashed grey lines the boundaries of the height classes.
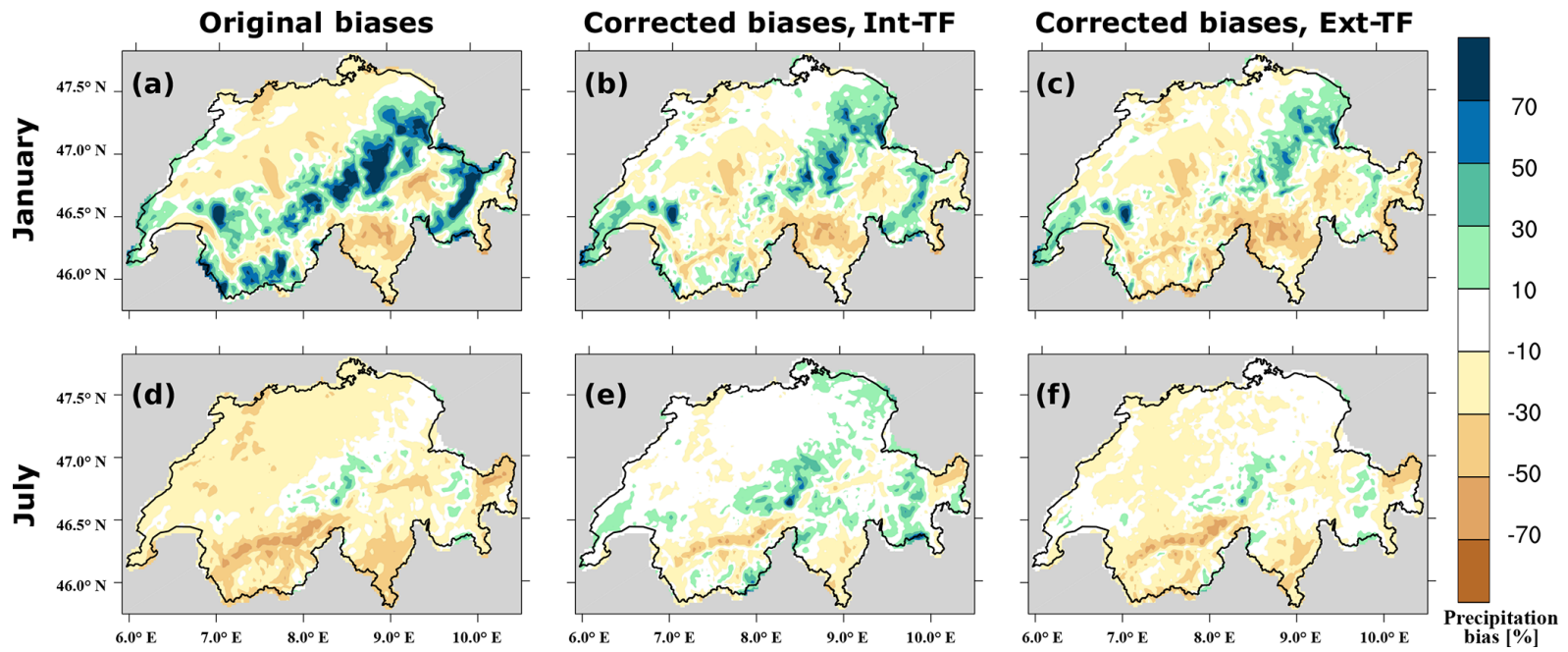

Figure 7. Biases in the climatological mean value of precipitation intensity over Switzerland. Panel (a) represents the original biases in January, (b) the biases after being corrected using Int-TFs in January, and (c) the biases after being corrected using Ext-TFs in January; panels (d), (e), and (f) are the same as (a), (b), and (c) but in July, respectively.

months, whereas they are generally smaller compared to the observations during warmer months. The biases are stronger than the ones observed in the climatological mean value (Fig. 7a and d), which means that the variability simulated by WRF is strongly season-dependent (Fig. 8a and d). The increase in variability during colder months is a hint that processes common during winter, e.g. the synoptic atmospheric systems, may be too efficient in producing precipitation compared to the observations. The reduced variability in warmer months hints at remaining problems in convective processes as these are more relevant during summer. Also, observations do not perfectly estimate the range due to their uncertainty that fluctuates from $5 \%$ over the flatland regions to more than $30 \%$ at high altitudes (Isotta et al., 2014).

Another important measure to characterise precipitation is the occurrence of precipitation at each grid point, defined by the wet-day frequency (the number of days with precipitation rate of at least $1 \mathrm{~mm} \mathrm{~d}^{-1}$ ). The wet-day frequency is strongly overestimated during colder months but shows only a slight overestimation during warmer months (Fig. 9a and d). This overestimation can be also related to the well-known problem in regional climate modelling, i.e. the simulation of a higher frequency in precipitation but at the same time with a lower intensity than observed (Murphy, 1999; Fowler et al., 

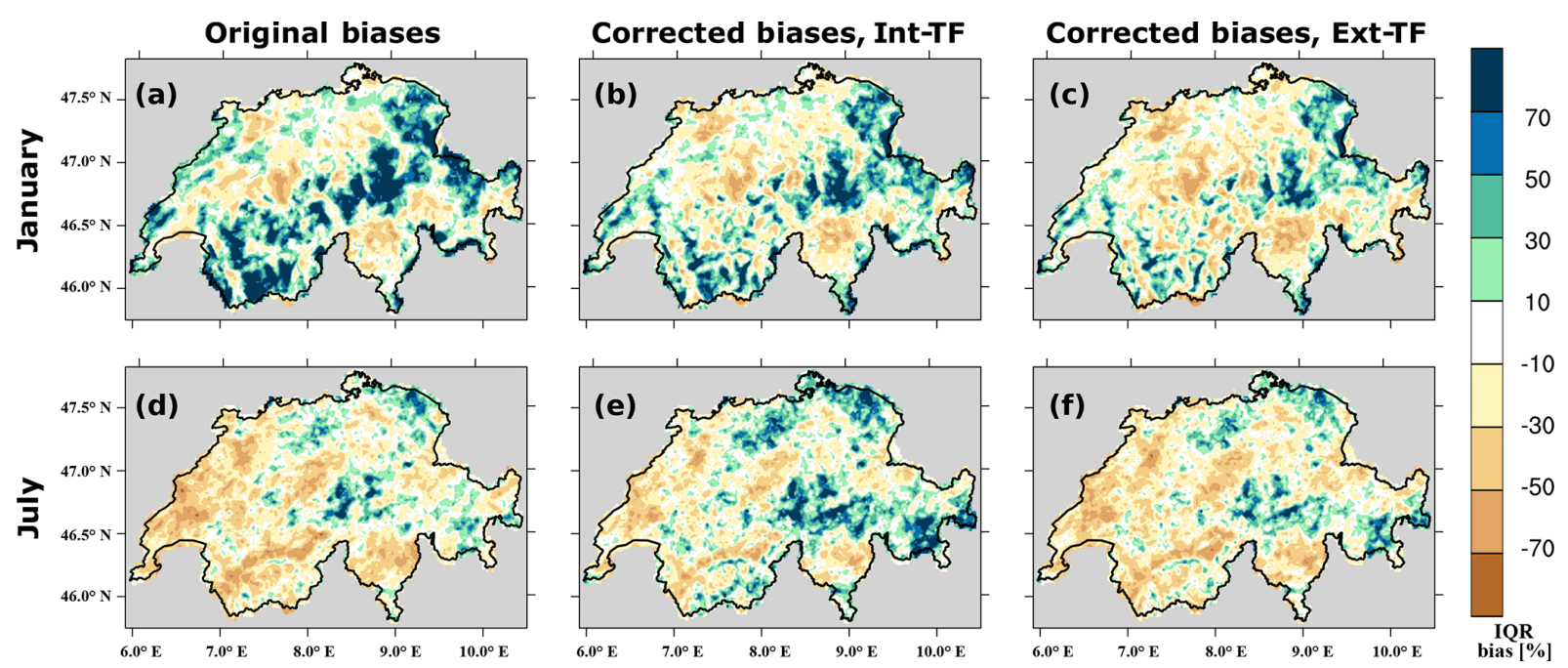

Figure 8. Biases in the interquartile range of monthly mean precipitation intensity over Switzerland. Panel (a) represents the original biases in January, (b) the biases after being corrected using Int-TFs in January, and (c) the biases after being corrected using Ext-TFs in January; panels (d), (e), and (f) are the same as (a), (b), and (c) but in July, respectively.

2007b; Maraun, 2013). The overestimation in wet-day frequency, the so-called drizzle effect, can be mainly related to the occurrence of synoptic atmospheric systems commonly observed during colder months and not to local convective processes that are frequently observed during summer (for climatology, see Frei and Schär, 1998; Isotta et al., 2014). Furthermore, the positive bias in the wet-day frequency may slightly contribute to the underestimation of the extreme precipitation (Fig. 5) as precipitable water, which is necessary for extreme precipitation events, is removed via the drizzle effect. Namely, the precipitable water available for a daily extreme precipitation event is distributed over several days due to problems in the parameterisations of the cloud microphysical and precipitation processes as found in Knist et al. (2018).

\subsection{Influence of different orographic characteristics on the performance of the bias-correction method}

Different orographic characteristics are suggested to be used as classification in the new bias-correction method (step 1 in Sect. 3): the height intervals (100 and $400 \mathrm{~m}$ ), the slope orientations, and a combination of both using the height interval of $400 \mathrm{~m}$ (combined features). Note that the results are not affected by interchanges in the order of the orographic characteristics in the combined features (therefore not shown). We assess, in the following, which of these characteristics are necessary to improve a simple approach of applying one EQM-TF to the entire domain, where orographic features are not considered. An improvement compared to one EQM-TF for the entire domain would certainly support the height dependence of the biases. Note that we do not compare our results to the standard EQM as the latter would outperform the here-described method by definition. Note that the stan- dard EQM removes the mean bias on a grid-point level as it is a statistical downscaling at the same time. We use Taylor diagrams (Fig. 10) for four months, namely, January, April, July, and September, as the biases show a strong seasonality (see previous section). The evaluation is carried out with three statistics: the spatial correlation, the spatial root-meansquare error, and the spatial standard deviation.

Figure 10a shows that the correction methods using height intervals of both 100 and $400 \mathrm{~m}$, and the combined features have better performance during the colder months than the other methods, i.e. using just orientation or one $\mathrm{TF}$ for the entire domain: the standard deviation is better adjusted, especially when using height intervals of $100 \mathrm{~m}$, the root-meansquare error is reduced by roughly $32 \%$, and the correlation is slightly increased (Fig. 10b). During the cold-to-warm transition months (here illustrated by April), the correction using height intervals of $400 \mathrm{~m}$ and the combined features have better performance than the other settings. This is because the standard deviation is fully adjusted, the root-meansquare error is reduced by $17 \%$, and the correlation is increased to $r=0.75$ (Fig. 10b). During the warmer months, all correction methods except the one using height intervals of $100 \mathrm{~m}$ show similar good performance; i.e. the standard deviation is fully adjusted, the root-mean-square error is slightly reduced, and the correlation is slightly increased (Fig. 10c). The similar good correction in the warm months can be explained by a reduced height dependence of the biases in these months. During the warm-to-cold transition months (September; Fig. 10d), all correction methods show a similar performance increase compared to the observations; correlation and root-mean-square error are only slightly improved. The method using height intervals of $100 \mathrm{~m}$ often reduces the standard deviation. This can be explained by a 

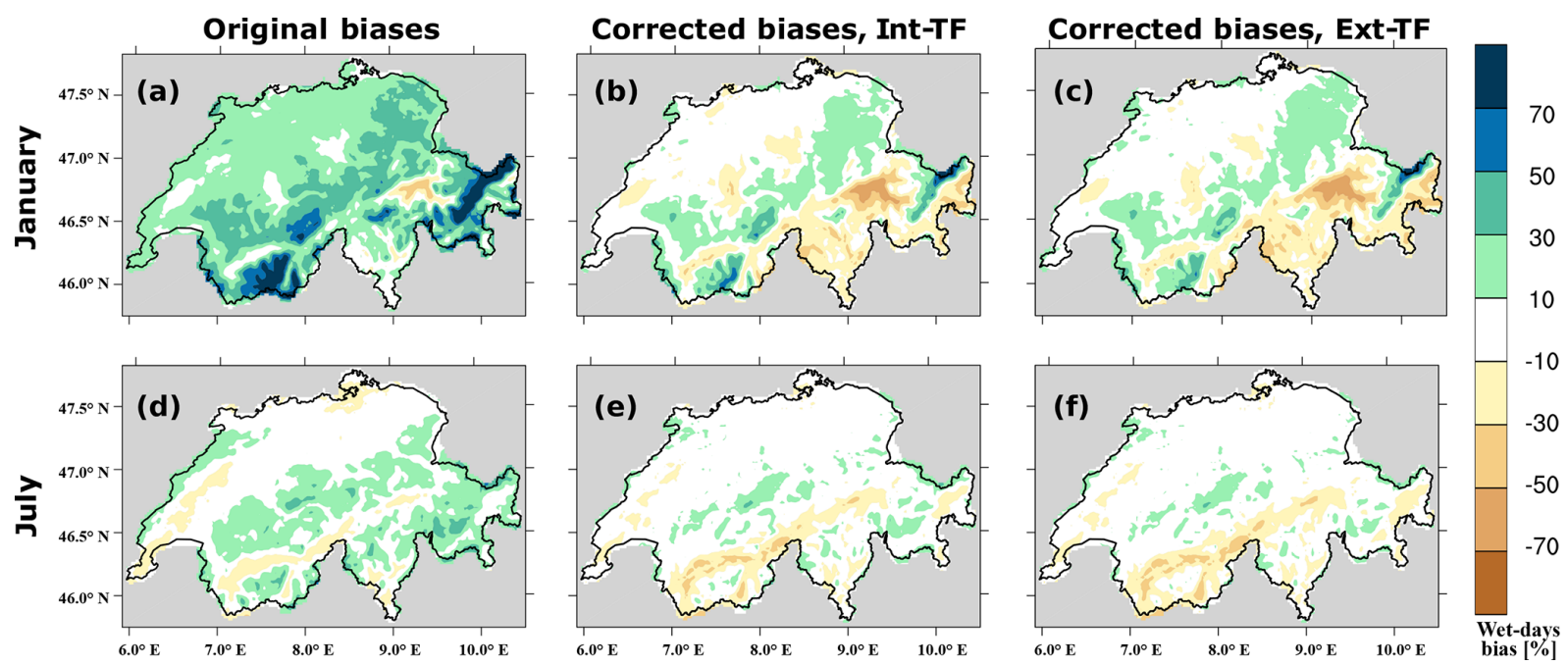

Figure 9. Biases in the wet-day frequency within the 30-year period over Switzerland. Panel (a) represents the original biases in January, (b) the biases after being corrected using Int-TFs in January, and (c) the biases after being corrected using Ext-TFs in January; panels (d), (e), and (f) are the same as (a), (b), and (c) but in July, respectively.

reduced data coverage which means less variability within some height classes as a smaller climatological range is encompassed by each height interval.

Even though all the settings mostly show good performance, the one using height intervals of $400 \mathrm{~m}$ outperforms in most measures and months. In addition, the correction method using the height intervals of $400 \mathrm{~m}$ needs less computational time compared to the similarly good correction method using height intervals of $400 \mathrm{~m}$ and slope orientations. Therefore, the method using height intervals of $400 \mathrm{~m}$ seems to be the most appropriate setting and is used in the following analysis.

\subsection{Application of the bias-correction method and cross-validation under present-day conditions}

The bias-correction method using height intervals of $400 \mathrm{~m}$ is now assessed in more detail. First, we focus on results where the TFs are estimated in the domain of Switzerland using 30 years (Int-TFs). Second, we discuss the results obtained by a temporal and spatial cross-validation technique, i.e. the TFs trained on another period and the TFs estimated with the surrounding Alpine region, excluding Switzerland (ExtTFs). As in Sect. 4.2, a comparison to the standard EQM (Lafon et al., 2013) is not presented, since the standard EQM outperforms the new method under present-day conditions. A priori, this comparison is based on different prerequisites, as the standard EQM corrects at a grid-point level, and thus it removes the mean biases as in statistical downscaling methods. Instead, we again compare the new method to a simple one EQM-TF used for all of Switzerland. A similar approach is sometimes used in other studies as well to assess the added value of their proposed methods (e.g. Gómez-Navarro et al., 2018; Casanueva et al., 2016).
To illustrate the improvement by the correction method using Int-TFs, we compare the spatial and temporal representation of the corrected precipitation with RhiresD. Focusing on the monthly mean precipitation intensity across Switzerland, we find that the climatological annual cycle of mean precipitation intensity fully coincides with the one of the observations (Fig. 5a). Also, the distributions of monthly mean precipitation intensity are fully adjusted and the corresponding interquartile ranges mainly correspond to the ones of the observations when using the new bias-correction method. Still, the extreme precipitation events are underestimated with the new method, which is expected as the TF of the extreme values is poorly constrained in the EQM approach (e.g. Themessl et al., 2011). The segregation into the height classes (Fig. 5b and c) shows that the climatological monthly means and the distributions of monthly mean precipitation intensity are also well adjusted compared to the observations. This illustrates that the bias-correction method using height intervals of $400 \mathrm{~m}$ is appropriate.

To further describe the spatial improvements of the new bias-correction method, we select here, as in Sect. 4.1, two months that mainly represent the colder and warmer months, e.g. January and July, respectively. We again focus on biases in the monthly mean precipitation intensity, in the variability illustrated by the interquartile range, and in the wet-day frequency.

A comparison of Fig. 7a and d with $b$ and e shows that the biases in the climatological mean precipitation intensity are substantially reduced, especially the overestimation over high mountain regions during colder months and the general underestimation during warmer months. Still, regions with positive and negative biases remain over the eastern part of the mountains in colder months and in the steep valleys like 
(a) January

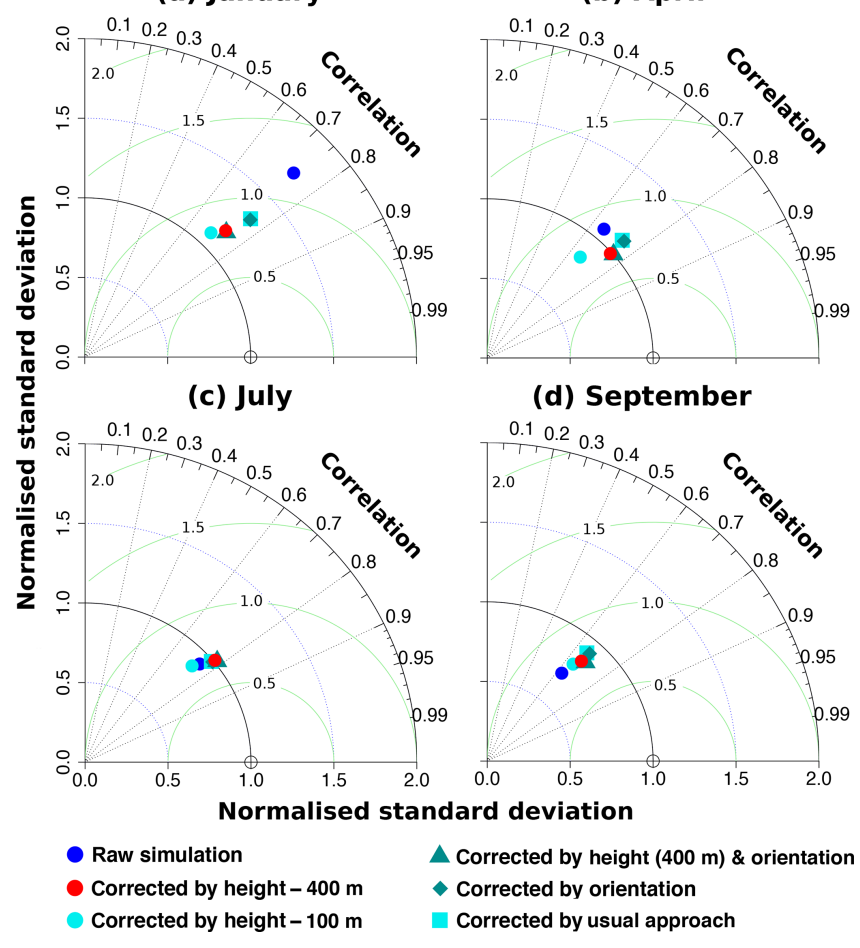

Figure 10. Performance of bias correction with different settings. Panel (a) shows a Taylor diagram for January, (b) for April, (c) for July, and (d) for September. Blue dots represent the raw simulation, red dots the simulation corrected by using height intervals of $400 \mathrm{~m}$, cyan dots the simulation corrected by using height intervals of $100 \mathrm{~m}$, petrol triangles the simulation corrected by using height intervals of $400 \mathrm{~m}$ and slope orientations, petrol diamonds the simulation corrected by slope orientations, and cyan squares the simulation corrected by the simple approach (the entire Swiss region). Note that in the Taylor diagram the spatial correlation, spatial rootmean-square error, and spatial standard deviation are shown.

the Rhône Valley in warmer months. Also, the negative bias in Ticino during colder months remains, albeit it is slightly ameliorated. The rather moderate performance in these regions can be traced back to the fact that some height classes sample over regions with different biases. Hence, biases of one area are diminished by the biases that are shared by the other areas. For instance, the strong negative biases observed in the Rhône Valley and Ticino are not fully decreased because the slight underestimation from the Swiss Plateau dominates this height class (Fig. $7 \mathrm{~b}$ and e).

To assess the improvements with respect to precipitation variability, we focus on the interquartile range of the distribution of monthly mean precipitation intensity at each grid point (Fig. $8 \mathrm{~b}$ and e compared to a and d). The biases of the interquartile range improve only moderately; i.e. the strong overestimation over the mountains is partly corrected during colder months but not during warmer months. The underestimation over the flatlands and steep valleys is corrected during warmer months and poorly during colder months.
For the wet-day frequency, we find that the positive biases are mostly reduced, especially the strong overestimation over the mountains during colder months (Fig. 9b and e). However, the regions of the Rhône Valley and Ticino, which show no biases in the raw model output, are slightly underestimated during colder months. The negative biases observed in the region of Grisons become stronger during colder months and in the region of the Rhône Valley during warmer months (Fig. 9b and e). This effect is again caused by sampling different regions with different biases in the height classes.

Recent studies by Maraun et al. (2017) and Maraun and Widmann (2018b) showed that the observational and simulated data sets do not have a synchronised internal climate variability, and thus this may be one of the sources of the remaining biases in free-running models. To assess these remaining biases, we perform a temporal cross-validation. An option could be to carry out a leave-one-out verification method to hold back most of the years for calibration; however, different lengths between calibration and the independent verification periods can lead to more uncertainties (Lafon et al., 2013; Maraun, 2016; Maraun et al., 2017; Maraun and Widmann, 2018b). Therefore, our temporal crossvalidation consists of using different same-length periods for the calibration and the verification (see Sect. 3). Overall, the bias-correction method performs similarly in the independent 15 years and shows similar remaining biases compared to using the entire 30 years for training and verification. Still, some differences between dependent and independent periods are evident. During January, the method trained on the first 15 years and verified in the second 15 years shows lower biases over high altitudes and slightly higher biases in the flatlands and in Ticino (not shown). Inversely, the method trained with the second 15 years and verified in the first 15 years shows reduced biases in the flatlands and in Ticino but not over the mountains (not shown). During July, similar small differences are identified in the independent verification periods (therefore not shown). Thus, there is a potential that a different internal climate variability affects the biascorrection method (Maraun et al., 2017; Maraun and Widmann, 2018b). However, these differences can be considered minimal as the accuracy of bias-correction methods is sensitive to the length of the period the methods are trained on (a shorter training period results in less accurate performance; Lafon et al., 2013).

To further check the robustness of the new bias-correction method, a spatial cross-validation is performed (see Sect. 3). Thereby, we apply the TFs estimated from an independent data set of the Alpine region (at $5 \mathrm{~km}$ resolution), excluding Switzerland (Ext-TFs), to the Swiss region (at $2 \mathrm{~km}$ resolution). To have insights into the effects of the correction method using Ext-TFs, we compare the spatial and temporal representation of the corrected precipitation with the results obtained by the Int-TFs. Note that the RhiresD is always used as observations for the bias calculation. Again, to describe the spatial effects, we select here two months that 
mainly represent the colder and warmer months, i.e. January and July, respectively.

A comparison of Fig. $7 \mathrm{~b}$ with $\mathrm{c}$ shows almost the same pattern; i.e. the improvement in mean precipitation achieved by using Ext-TFs is similar to that using the Int-TFs during colder months. Still, some positive biases over the mountains seem to be smaller when using Ext-TFs than Int-TFs, whereas the remaining negative biases are slightly stronger than the ones after using Int-TFs (Fig. 7b and c). The reason for the latter could lie in the inclusion of larger regions in the north and west of the Alps mixing different climate conditions and thus bias behaviours. The slightly better performance in the mountain regions is probably related to more data being available in these height classes, i.e. more grid points at high altitudes (Fig. 2), and thus it is possible to better constrain the TFs. In the warmer months, we find that the method using Ext-TFs shows slightly more negative biases than with Int-TFs, in particular over the Swiss Plateau. Again, we hypothesise that the inclusion of larger regions in the north and west of the Alps is responsible for this bias behaviour.

The interquartile ranges of the distribution of monthly mean precipitation intensity are similar when using either Ext-TFs or Int-TFs for the colder months (Fig. 8c compared to $b)$. During warmer months, the negative biases in the western part of Switzerland are less improved using Ext-TFs than Int-TFs, which is again a hint that the inclusion of larger regions in the north and west of the Alps in the lower height classes plays a role in the bias of the interquartile range.

The wet-day frequencies are very similarly corrected as in the approach using Ext-TFs compared to Int-TFs (Fig. 9c and f compared to $b$ and e). Thus, the wet-day frequency seems to be insensitive to the region where the TFs are estimated.

Additionally, to further assess the local improvements of adding topographic features into the correction, we analyse the remaining biases of the simple method using TFs deduced for the Swiss region (Int-TFs), as described in Sect. 4.2, and for the corresponding Alpine region (ExtTFs) separately. Overall, the comparison between the simple method and the new method shows small differences (therefore not shown). The new method shows better performance than the simple method in January but similar performance in July. Furthermore, the simple method increases the original biases over the flatlands, which are reduced by the new bias correction. This confirms the results of the Taylor diagram illustrated in the Fig. 10, i.e. the better performance of the method using height intervals of $400 \mathrm{~m}$.

In summary, the new correction method reasonably well corrects biases in the monthly mean precipitation intensity, in the variability illustrated by the interquartile range, and in the wet-day frequency. The two cross-validations show that the improvements achieved by the new method are almost independent of the time period and region used to estimate the TFs. Additionally, the new method outperforms the simple method (one EQM-TF) in the present-day climate.

\subsection{Application of bias-correction methods on the simulated LGM climate}

To further examine the performance and applicability of the new bias-correction method, we apply it to the simulated LGM climate. Similarly, the standard EQM (e.g. Lafon et al., 2013; Teutschbein and Seibert, 2012, 2013; Teng et al., 2015) is applied and precipitation fields resulting from its correction are compared to the one of the new method. The reason is that the strength of the standard EQM (correction at grid-point level) under present-day climate might be a weakness under highly different climate states, since localrelated biases might not exist. To that end, we again focus on the monthly mean precipitation intensity over Switzerland in January and July, i.e. the two months that represent the cold and warm seasons, respectively.

Focusing on the raw LGM simulation first, we find wetter conditions in the southern part of the Swiss Alps (Fig. 11a and d) rather than at the north-facing slopes, as is the case in present-day conditions (more details about present-day conditions are available in Frei and Schär, 1998; Schwarb et al., 2001). Becker et al. (2016) indicated a strong precipitation gradient between the north- and the south-facing slopes in order to obtain a reasonable extent of the Alpine glacier during the LGM. This suggests an increase of intensity or frequency of the southerly moisture advection over the Alps. Also, Florineth and Schlüchter (2000) and Luetscher et al. (2015) indicated a circulation change from dominant westerlies in the present day to a more southerly atmospheric circulation during the LGM. From this brief qualitative analysis, we can conclude that WRF reasonably simulates the precipitation patterns during the LGM, even if the total amount might present some uncertainties.

Before assessing the performance of the two biascorrection methods, it is worthwhile to shortly focus on the changes in the topography. The topography is differently lifted across Switzerland during the LGM (Fig. 3b) compared to the present-day climate (Fig. 2). While the mountainous areas become larger, the height of their peaks hardly changes. The present-day valleys are filled by ice during the LGM, and thus the deep valleys almost disappear. For instance, the Rhône Valley exhibits a continuous slope towards its spring (Fig. 3b), while it is a narrow and deep valley with almost a constant elevation in the present-day topography (Fig. 2). Since the Alps were covered by ice, the fine and complex present-day topography is lacking during the LGM.

We apply the standard EQM and the new method to not only assess their performance but also to identify the strength and weakness of each method. Comparing Fig. $11 \mathrm{~b}$ and e to $\mathrm{c}$ and f illustrates that the corrections do not modify the northsouth precipitation gradient observed in the raw simulation (Fig. 11a and d). The standard EQM method (Fig. 12b and d) shows that the shape of the valleys and the mountain peaks of the present-day topography are imprinted on the raw LGM climate (Fig. 12a and c). The standard EQM seems to add a 
Original LGM
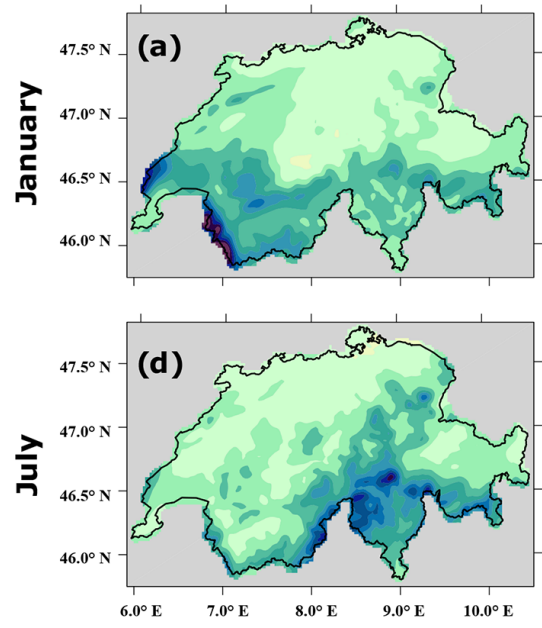

Corrected LGM

Standard method
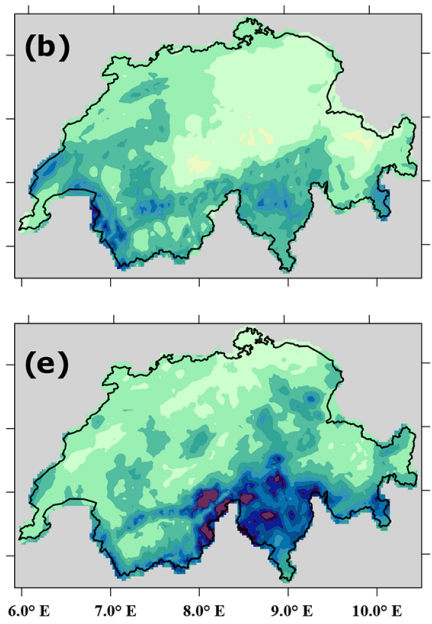
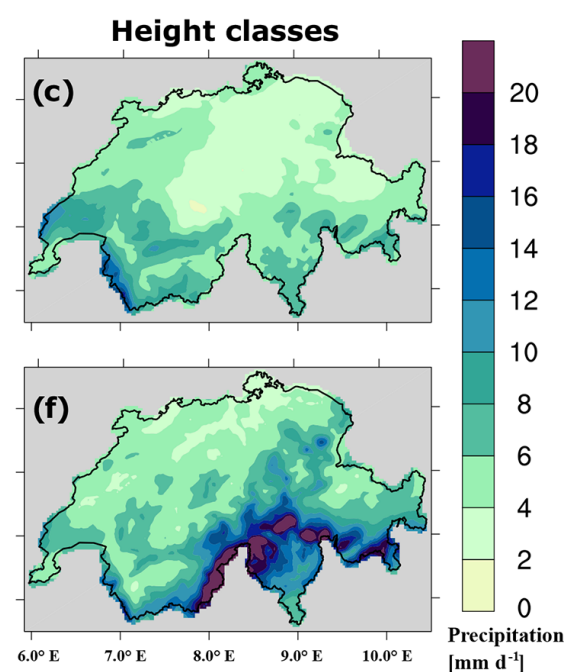

Figure 11. Monthly climatology of 30-year precipitation over Switzerland during the LGM. Panel (a) represents uncorrected precipitation intensity in January; panel (b) is the same as (a) but corrected using the standard EQM; panel (c) is the same as (b) but using the new method; panels (d), (e), and (f) are the same as (a), (b), and (c) but for July, respectively.

fine and complex structure to the precipitation pattern. This complexity is hardly justified over the Alps during the LGM, as stated before, which suggests that adding this structure is unnecessary. The imprint of the present-day topography is related to the nature of the standard EQM that trains the TFs point-wise assuming static orographic features. The new correction method follows by definition the LGM topography showing a smoother correction for the LGM climate, which provides precipitation patterns that more appropriately represent the LGM situation. Proxy records could give an idea on the LGM precipitation amounts but there is a very limited number of them in Switzerland; thus, a more rigorous analysis of the application of the two methods to the LGM climate is not possible. However, the difference between the two methods demonstrates that the application of the new bias correction is better suited than the standard EQM. Therefore, we consider it as more appropriate for climate states with strongly altered topography compared to today.

\section{Summary and conclusions}

In this study, we present a new bias-correction method for precipitation over complex topography, which takes orographic characteristics into account. This method is mainly designed for climate states where the topography is distinctively different to the present-day one, i.e. glacial times. This is particularly important for studies where absolute values of precipitation are essential, such as glacier and ice sheet modelling (Seguinot et al., 2014; Jouvet et al., 2017; Jouvet and Huss, 2019), and the assessment of human behaviour during glacial times (Burke et al., 2017; Wren and Burke, 2019). To illustrate the performance of the new method, two regional climate model simulations are performed with WRF at $2 \mathrm{~km}$ resolution over the Alpine region. We particularly focus on the performance over Switzerland.

The comparison between the WRF simulation and the observations over Switzerland shows that the biases are season dependent and related to the complexity of the topography, especially in colder months (November to March). These months exhibit positive biases over mountains and negative biases in steep valleys, whereas negative biases dominate during the warmer months (April to October), especially in the Rhône Valley and Ticino. Parts of the biases are introduced by the driving global climate model, in particular the seasonal biases (Gómez-Navarro et al., 2018). Moreover, the large-scale atmospheric circulation of the global climate model is too zonal - a known problem in many models (e.g. Raible et al., 2005; Raible et al., 2014; Hofer et al., 2012a, b; Mitchell et al., 2017) - which cannot be fully compensated for by the RCM. Thus, the wet bias present in the global simulation (Hofer et al., 2012a, b) may be transported into the regional model domain, rendering especially the colder months with more precipitation. Still, observations are also not perfect and underestimate precipitation in particular at high altitudes by up to $30 \%$ (Isotta et al., 2014). Other biases are potentially induced by the RCM; e.g. a WRF simulation using a similar setting but driven by ERA-Interim (GómezNavarro et al., 2018) shows also a comparable overestimation of precipitation over mountain regions as the simulation used in this study. In addition, we find that the extreme precipitation values are underestimated. This is due to the drizzle effect (Murphy, 1999; Fowler et al., 2007b) that can remove moisture needed for the extreme precipitation, which mainly comes from physical parameterisations of the model itself 


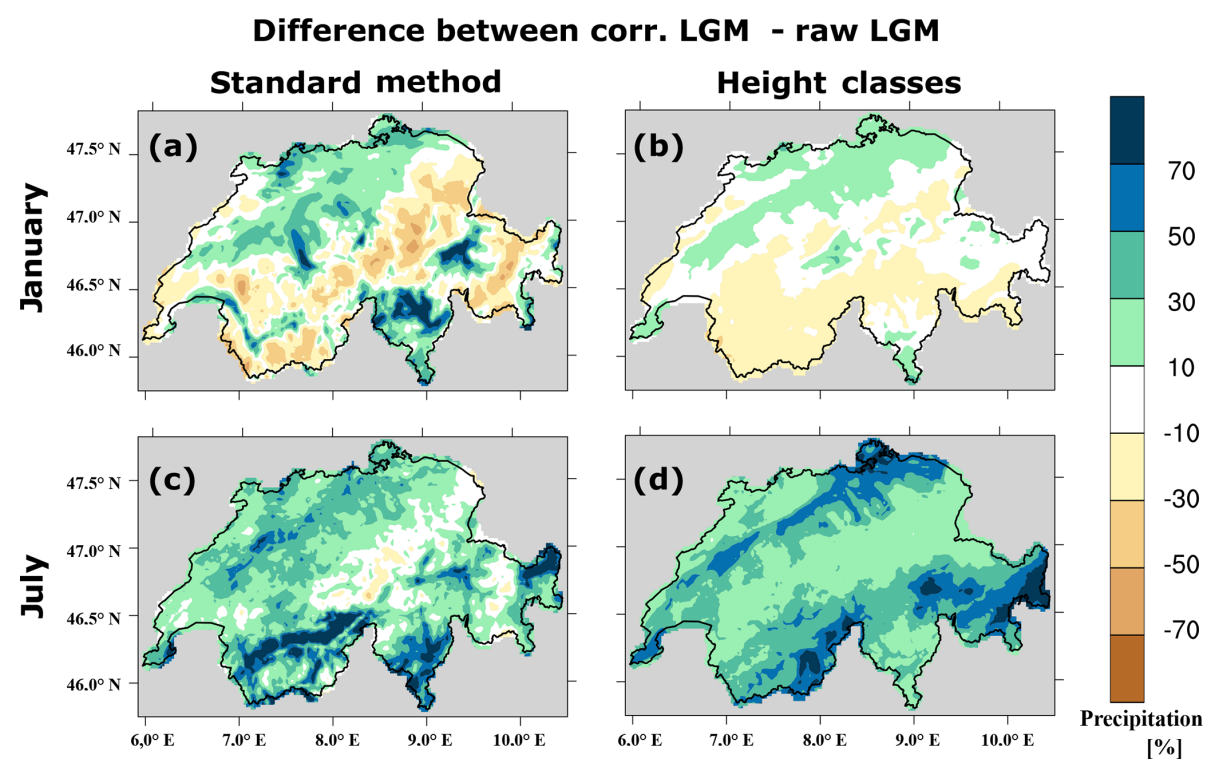

Figure 12. Performance of the correction for the monthly climatology of 30-year precipitation over Switzerland during the LGM. Panel (a) represents the differences in January between corrected precipitation using the standard EQM and uncorrected precipitation; panel (b) is the same as (a) but using the new method; panels (c) and (d) are the same as (a) and (b) but in July, respectively.

(Solman et al., 2008; Menéndez et al., 2010; Gianotti et al., 2011; Carril et al., 2012; Jerez et al., 2013). A hint for this is given by the fact that the wet-day frequency in the simulation is enhanced compared to the observations.

Numerous approaches to correct biases exist (e.g. Maraun, 2013; Teng et al., 2015; Casanueva et al., 2016; Ivanov et al., 2018); nevertheless, they assume stationary orographic features that are then imprinted onto the other climate state when applying the correction. Hence, an alternative method is needed, which reduces this assumption so that it adds value to especially colder climate states characterised by a strongly changed topography, such as the LGM. The new method consists of three steps: the orographic characteristics differentiation, the adjustment of very low precipitation intensities, and the EQM. Different orographic characteristics, i.e. the height intervals, the slope orientations, and the combination of both, are tested showing that the method using height intervals of $400 \mathrm{~m}$ is generally the most skilful correction compared to other orographic characteristics and at the same time it is computationally the most efficient one. In the colder months, the new method outperforms the simple method of applying one EQM-TF that is deduced for the entire region of interest and does not consider any orographic features.

Applying the new bias-correction method to the Swiss region exclusively shows that the biases are mostly corrected. In particular, the distribution of the monthly precipitation across Switzerland is mainly adjusted, the mean precipitation biases are substantially reduced, and the biases in the wet-day frequency are mostly reduced. The method better corrects the positive biases during colder than warmer months, and conversely, the negative biases during warmer than colder months. However, some biases are still observed, which is explained by the fact that some height classes sample over regions with different biases. Also, the deficient constraint of the TFs in outermost quantiles poorly corrects extreme values, i.e. below the first quantile and above the last quantile. Furthermore, part of the remaining biases may also be interpreted as possible error propagation, which initially comes from the interpolation methods and "gauge undercatch" in the gridded observational data sets, especially at high altitudes where less data are available (for more details, see Sevruk, 1985; Richter, 1995; Isotta et al., 2014).

The new method is temporally and spatially crossvalidated. The 30 -year period is split in a 15 -year training and a 15 -year independent temporal verification part. The results are similar to the case when the TFs are trained on and applied to the 30 -year period. Still, such a cross-validation might be problematic as the method's accomplishment relies on the biases caught during the period the method is trained on, i.e. the asynchronism in the internal climate variability of the data sets (Maraun et al., 2017; Maraun and Widmann, 2018a). Maraun and Widmann (2018a) argued that crossvalidation methods shall compare the correction with the observations on different climate states, i.e. the future or past climate state; otherwise, they can produce false positive or true negative results. To overcome some of these possible limitations, we apply a spatial cross-validation that checks the transferability of the bias-correction method to a different climate state. We use an independent data set of the Alpine region (APGD) excluding Switzerland when estimating the transfer functions (Ext-TFs). This shows a similar improve- 
ment compared to the correction performed with data over the Swiss region exclusively (Int-TFs).

The applicability of the new method is further assessed under LGM climate conditions. There is a very limited amount of proxy evidence in Switzerland for a rigorous evaluation. Thus, we compare the performance of the new biascorrection method and the standard EQM when they are applied to LGM climate conditions. The standard EQM adds features to the precipitation that can hardly be justified in the LGM, whereas the performance of the new method suits it better. This indicates that the new method is safer and therefore more appropriate than the standard EQM under LGM climate conditions. In a similar manner, the new method may also be better suited in some regions for future climate scenarios. This is especially true for areas that are currently covered by ice, such as the Himalayas, since possible melting of glaciers can change the shape of the already complex terrain in the future.

Finally, a common drawback of all bias-correction methods (including the one presented in this study) is that they ignore a potential modification of the bias structure due to the handling of rainfall and snowfall in the model's microphysics. This is certainly important when the bias-correction method shall be used in cold climate states, like the LGM. Currently, there are no gridded and homogenised observations available for snowfall, which is needed for a rigorous analysis of this effect. Still, our seasonally separated and height-dependent method implicitly includes some aspects of the handling of rainfall and snowfall, since one can expect that most of the precipitation is snow at high altitudes and in colder months. Clearly, future work is needed on this aspect as soon as reliable observations of snowfall are available. Additionally, other variables of the Earth's system need to be assessed in future studies on bias-correction methods, especially the response of soil moisture and snow albedo to the corrected precipitation patterns. In the meantime, glaciologists can benefit from a better accuracy of precipitation data obtained by the new method for, e.g. LGM conditions. Glacier modelling (Seguinot et al., 2014; Jouvet et al., 2017; Jouvet and Huss, 2019) results may provide an alternative method for the validation when evaluating the prediction and proxy data of the glacier extents.

Code and data availability. WRF is a community model that can be downloaded from its web page (https: //www2.mmm.ucar.edu/wrf/users/index.html, last access: 12 October 2020) (Skamarock et al., 2005). The two climate simulations (global: CCSM4 and regional: WRF) occupy several terabytes and thus are not freely available. Nevertheless, they can be accessed upon request to the contributing authors. The post-processed daily precipitation that is used to perform the bias correction is archived on Zenodo at https://doi.org/10.5281/zenodo.4009101 (Velasquez et al., 2019). The RhiresD and APGD data sets can be requested from MeteoSwiss. Simple calculations carried out at a grid-point level are performed with Climate Data
Operators (CDO; https://doi.org/10.5281/zenodo.2558193; Schulzweida, 2019) and NCAR Command Language (NCL; https://doi.org/10.5065/D6WD3XH5; UCAR/NCAR/CISL/TDD, 2019). The data in the figures are obtained with NCL (UCAR/NCAR/CISL/TDD, 2019) and RStudio (RStudio Team, 2015). The codes to perform the bias correction, the simple calculations, and the figures are archived on Zenodo (https://doi.org/10.5281/zenodo.4009101; Velasquez et al., 2019).

Author contributions. PV, MM, and CCR contributed to the design of the experiments. PV carried out the simulations and wrote the first draft. All authors contributed to the internal review of the text prior to the submission.

Competing interests. The authors declare that they have no conflict of interest.

Acknowledgements. Martina Messmer acknowledges support by the SNF (Early Postdoc.Mobility). The CCSM4 and WRF simulations were performed on the supercomputing architecture of the Swiss National Supercomputing Centre (CSCS). Thanks are due to European Reanalysis and Observations for Monitoring for providing APGD.

Financial support. This research has been supported by the Swiss National Science Foundation (grant no. 200021_162444).

Review statement. This paper was edited by Fabien Maussion and reviewed by three anonymous referees.

\section{References}

Allen, M. R. and Ingram, W. J.: Constraints on future changes in climate and the hydrologic cycle, Nature, 419, 228-232, https://doi.org/10.1038/nature01092, 2002.

Amengual, A., Homar, V., Romero, R., Alonso, S., and Ramis, C.: A statistical adjustment of regional climate model outputs to local scales: Application to Platja de Palma, Spain, J. Climate, 25, 939-957, https://doi.org/10.1175/JCLI-D-10-05024.1, 2011.

Andréasson, J., Bergström, S., Carlsson, B., Graham, L. P., and Lindström, G.: Hydrological change - climate change impact simulations for Sweden, Ambio, 33, 228-234, https://doi.org/10.1579/0044-7447-33.4.228, 2004.

Auer, I., Böhm, R., and Schöner, W.: Austrian long-term climate 1767-2000, Osterreichische Beiträge zu Meteorologie und Geophysik, 25, 147, ISSN 1016-6254, 2001.

Ban, N., Schmidli, J., and Schär, C.: Evaluation of the convectionresolving regional climate modeling approach in decadelong simulations, J. Geophys. Res.-Atmos., 119, 7889-7907, https://doi.org/10.1002/2014JD021478, 2014.

Bartlein, P. J., Harrison, S. P., Brewer, S., Connor, S., Davis, B. A. S., Gajewski, K., Guiot, J., Harrison-Prentice, T. I., Hender- 
son, A., Peyron, O., Prentice, I. C., Scholze, M., Seppä, H., Shuman, B., Sugita, S., Thompson, R. S., Viau, A. E., Williams, J., and $\mathrm{Wu}, \mathrm{H}$. : Pollen-based continental climate reconstructions at 6 and 21 ka: a global synthesis, Clim. Dynam., 37, 775-802, https://doi.org/10.1007/s00382-010-0904-1, 2011.

Becker, P., Seguinot, J., Jouvet, G., and Funk, M.: Last Glacial Maximum precipitation pattern in the Alps inferred from glacier modelling, Geogr. Helv., 71, 173-187, https://doi.org/10.5194/gh-71173-2016, 2016.

Bennett, J. C., Grose, M. R., Corney, S. P., White, C. J., Holz, G. K., Katzfey, J. J., Post, D. A., and Bindoff, N. L.: Performance of an empirical bias-correction of a highresolution climate dataset, Int. J. Climatol., 34, 2189-2204, https://doi.org/10.1002/joc.3830, 2014.

Berg, P., Feldmann, H., and Panitz, H. J.: Bias correction of high resolution regional climate model data, J. Hydrol., 448-449, 8092, https://doi.org/10.1016/j.jhydrol.2012.04.026, 2012.

Berthou, S., Kendon, E. J., Chan, S. C., Ban, N., Leutwyler, D., Schär, C., and Fosser, G.: Pan-European climate at convectionpermitting scale: a model intercomparison study, Clim. Dynam., 55, 35-59, https://doi.org/10.1007/s00382-018-4114-6, 2018.

Boer, G. J.: Climate change and the regulation of the surface moisture and energy budgets, Clim. Dynam., 8, 225-239, https://doi.org/10.1007/BF00198617, 1993.

Burke, A., Kageyama, M., Latombe, G., Fasel, M., Vrac, M., Ramstein, G., and James, P. M. A.: Risky business: The impact of climate and climate variability on human population dynamics in Western Europe during the Last Glacial Maximum, Quaternary Sci. Rev., 164, 217-229, https://doi.org/10.1016/j.quascirev.2017.04.001, 2017.

Cannon, A. J., Sobie, S. R., and Murdock, T. Q.: Bias correction of GCM precipitation by quantile mapping: How well do methods preserve changes in quantiles and extremes?, J. Climate, 28, 6938-6959, https://doi.org/10.1175/JCLI-D-14-00754.1, 2015.

Carril, A. F., Menéndez, C. G., Remedio, A. R. C., Robledo, F., Sörensson, A., Tencer, B., Boulanger, J.-P., de Castro, M., Jacob, D., Le Treut, H., Li, L. Z. X., Penalba, O., Pfeifer, S., Rusticucci, M., Salio, P., Samuelsson, P., Sanchez, E., and Zaninelli, P.: Performance of a multi-RCM ensemble for south eastern South America, Clim. Dynam., 39, 2747-2768, https://doi.org/10.1007/s00382-012-1573-z, 2012.

Casanueva, A., Kotlarski, S., Herrera, S., Fernández, J., Gutiérrez, J. M., Boberg, F., Colette, A., Christensen, O. B., Goergen, K., Jacob, D., Keuler, K., Nikulin, G., Teichmann, C., and Vautard, R.: Daily precipitation statistics in a EUROCORDEX RCM ensemble: Added value of raw and biascorrected high-resolution simulations, Clim. Dynam., 47, 719737, https://doi.org/10.1007/s00382-015-2865-x, 2016.

Chen, H., Xu, C.-Y., and Guo, S.: Comparison and evaluation of multiple GCMs, statistical downscaling and hydrological models in the study of climate change impacts on runoff, J. Hydrol., 434435, 36-45, https://doi.org/10.1016/j.jhydrol.2012.02.040, 2012.

Chen, J., Brissette, F. P., Chaumont, D., and Braun, M.: Finding appropriate bias correction methods in downscaling precipitation for hydrologic impact studies over North America, Water Resour. Res., 49, 4187-4205, https://doi.org/10.1002/wrcr.20331, 2013.

Chen, W., Zhu, D., Ciais, P., Huang, C., Viovy, N., and Kageyama, M.: Response of vegetation cover to $\mathrm{CO} 2$ and climate changes between Last Glacial Maximum and pre-industrial period in a dy- namic global vegetation model, Quaternary Sci. Rev., 218, 293 305, https://doi.org/10.1016/j.quascirev.2019.06.003, 2019.

Clark, P. U., Dyke, A. S., Shakun, J. D., Carlson, A. E., Clark, J., Wohlfarth, B., Mitrovica, J. X., Hostetler, S. W., and McCabe, A. M.: The Last Glacial Maximum, Science, 325, 710 714, https://doi.org/10.1126/science.1172873, 2009.

Ehlers, J., Gibbard, P., and Hughes, P.: Quaternary glaciationsextent and chronology: a closer look, 15, Elsevier, Amsterdam, the Netherlands, 2011.

Fang, G. H., Yang, J., Chen, Y. N., and Zammit, C.: Comparing bias correction methods in downscaling meteorological variables for a hydrologic impact study in an arid area in China, Hydrol. Earth Syst. Sci., 19, 2547-2559, https://doi.org/10.5194/hess-19-25472015, 2015.

Felder, G., Gómez-Navarro, J. J., Zischg, A. P., Raible, C. C., Röthlisberger, V., Bozhinova, D., Martius, O., and Weingartner, R.: From global circulation to local flood loss: Coupling models across the scales, Sci. Total Environ., 635, 1225-1239, https://doi.org/10.1016/j.scitotenv.2018.04.170, 2018.

Finney, D. L., Marsham, J. H., Jackson, L. S., Kendon, E. J., Rowell, D. P., Boorman, P. M., Keane, R. J., Stratton, R. A., and Senior, C. A.: Implications of improved representation of convection for the East Africa water budget using a convection-permitting model, J. Climate, 32, 2109-2129, https://doi.org/10.1175/JCLID-18-0387.1, 2019.

Florineth, D. and Schlüchter, C.: Alpine Evidence for Atmospheric Circulation Patterns in Europe during the Last Glacial Maximum, Quaternary Res., 54, 295-308, https://doi.org/10.1006/qres.2000.2169, 2000.

Fowler, H. J., Blenkinsop, S., and Tebaldi, C.: Linking climate change modelling to impacts studies: Recent advances in downscaling techniques for hydrological modelling, Int. J. Climatol., 27, 1547-1578, https://doi.org/10.1002/joc.1556, 2007a.

Fowler, H. J., Ekström, M., Blenkinsop, S., and Smith, A. P.: Estimating change in extreme European precipitation using a multimodel ensemble, J. Geophys. Res.-Atmos., 112, D18 104, https://doi.org/10.1029/2007JD008619, 2007b.

Frei, C. and Schär, C.: A precipitation climatology of the Alps from high-resolution rain-gauge observations, Int. J. Climatol., 18, 873-900, https://doi.org/10.1002/(SICI)10970088(19980630)18:8<873::AID-JOC255>3.0.CO;2-9, 1998.

Frei, C., Christensen, J. H., Déqué, M., Jacob, D., Jones, R. G., and Vidale, P. L.: Daily precipitation statistics in regional climate models: Evaluation and intercomparison for the European Alps, J. Geophys. Res.-Atmos., 108, 4124, https://doi.org/10.1029/2002JD002287, 2003.

$\mathrm{Fu}, \mathrm{Q}$.: An accurate parameterization of the solar radiative properties of cirrus clouds for climate models, J. Climate, 9, 2058-2082, https://doi.org/10.1175/15200442(1996)009<2058:AAPOTS>2.0.CO;2, 1996.

Ganopolski, A. and Calov, R.: The role of orbital forcing, carbon dioxide and regolith in $100 \mathrm{kyr}$ glacial cycles, Clim. Past, 7, 1415-1425, https://doi.org/10.5194/cp-7-1415-2011, 2011.

Gent, P. R., Danabasoglu, G., Donner, L. J., Holland, M. M., Hunke, E. C., Jayne, S. R., Lawrence, D. M., Neale, R. B., Rasch, P. J., Vertenstein, M., Worley, P. H., Yang, Z.-L., and Zhang, M.: The Community Climate System Model Version 4, J. Climate, 24, 4973-4991, https://doi.org/10.1175/2011JCLI4083.1, 2011. 
Gianotti, R. L., Zhang, D., and Eltahir, E. A. B.: Assessment of the regional climate model version 3 over the maritime continent using different cumulus parameterization and land surface schemes, J. Climate, 25, 638-656, https://doi.org/10.1175/JCLID-11-00025.1, 2011.

Giorgi, F., Torma, C., Coppola, E., Ban, N., Schär, C., and Somot, S.: Enhanced summer convective rainfall at Alpine high elevations in response to climate warming, Nat. Geosci., 9, 584-589, https://doi.org/10.1038/ngeo2761, 2016.

Gómez-Navarro, J. J., Raible, C. C., Bozhinova, D., Martius, O., García Valero, J. A., and Montávez, J. P.: A new regionaware bias-correction method for simulated precipitation in areas of complex orography, Geosci. Model Dev., 11, 2231-2247, https://doi.org/10.5194/gmd-11-2231-2018, 2018.

Güttler, I., Stepanov, I., Branković, Č., Nikulin, G., and Jones, C.: Impact of horizontal resolution on precipitation in complex orography simulated by the regional climate model RCA3, Mon. Weather Rev., 143, 3610-3627, https://doi.org/10.1175/MWRD-14-00302.1, 2015.

Haslinger, K., Anders, I., and Hofstätter, M.: Regional climate modelling over complex terrain: An evaluation study of COSMOCLM hindcast model runs for the greater Alpine region, Clim. Dynam., 40, 511-529, https://doi.org/10.1007/s00382012-1452-7, 2013.

Hay, L. E., Wilby, R. L., and Leavesley, G. H.: A Comparison of delta change and downscaled GCM scenarios for three mountainous basins in the United States, J. Am. Water Resour. As., 36, 387-397, https://doi.org/10.1111/j.17521688.2000.tb04276.x, 2000.

Hofer, D., Raible, C. C., Dehnert, A., and Kuhlemann, J.: The impact of different glacial boundary conditions on atmospheric dynamics and precipitation in the North Atlantic region, Clim. Past, 8, 935-949, https://doi.org/10.5194/cp-8-935-2012, 2012a.

Hofer, D., Raible, C. C., Merz, N., Dehnert, A., and Kuhlemann, J.: Simulated winter circulation types in the North Atlantic and European region for preindustrial and glacial conditions: Glacial circulation types, Geophys. Res. Lett., 39, L15805, https://doi.org/10.1029/2012GL052296, 2012b.

Hui, P., Tang, J., Wang, S., Wu, J., Niu, X., and Kang, Y.: Impact of resolution on regional climate modeling in the source region of Yellow River with complex terrain using RegCM3, Theor. Appl. Climatol., 125, 365-380, https://doi.org/10.1007/s00704015-1514-y, 2016.

Isotta, F. A., Frei, C., Weilguni, V., Perčec Tadić, M., Lassègues, P., Rudolf, B., Pavan, V., Cacciamani, C., Antolini, G., Ratto, S. M., Munari, M., Micheletti, S., Bonati, V., Lussana, C., Ronchi, C., Panettieri, E., Marigo, G., and Vertačnik, G.: The climate of daily precipitation in the Alps: Development and analysis of a highresolution grid dataset from pan-Alpine rain-gauge data, Int. J. Climatol., 34, 1657-1675, https://doi.org/10.1002/joc.3794, 2014.

Ivanov, M. A., Luterbacher, J., and Kotlarski, S.: Climate model biases and modification of the climate change signal by intensity-dependent bias correction, J. Climate, 31, 6591-6610, https://doi.org/10.1175/JCLI-D-17-0765.1, 2018.

Jerez, S., Montavez, J. P., Jimenez-Guerrero, P., GomezNavarro, J. J., Lorente-Plazas, R., and Zorita, E.: A multiphysics ensemble of present-day climate regional simulations over the Iberian Peninsula, Clim. Dynam., 40, 3023-3046, https://doi.org/10.1007/s00382-012-1539-1, 2013.

Jouvet, G. and Huss, M.: Future retreat of Great Aletsch Glacier, J. Glaciol., 65, 869-872, https://doi.org/10.1017/jog.2019.52, 2019.

Jouvet, G., Seguinot, J., Ivy-Ochs, S., and Funk, M.: Modelling the diversion of erratic boulders by the Valais Glacier during the last glacial maximum, J. Glaciol., 63, 487-498, https://doi.org/10.1017/jog.2017.7, 2017.

Kageyama, M., Harrison, S. P., Kapsch, M.-L., Löfverström, M., Lora, J. M., Mikolajewicz, U., Sherriff-Tadano, S., Vadsaria, T., Abe-Ouchi, A., Bouttes, N., Chandan, D., LeGrande, A. N., Lhardy, F., Lohmann, G., Morozova, P. A., Ohgaito, R., Peltier, W. R., Quiquet, A., Roche, D. M., Shi, X., Schmittner, A., Tierney, J. E., and Volodin, E.: The PMIP4-CMIP6 Last Glacial Maximum experiments: preliminary results and comparison with the PMIP3-CMIP5 simulations, Clim. Past Discuss., https://doi.org/10.5194/cp-2019-169, in review, 2020.

Kaplan, J. O., Pfeiffer, M., Kolen, J. C. A., and Davis, B. A. S.: Large scale anthropogenic reduction of forest cover in Last Glacial Maximum Europe, PLoS One, 11, e0166 726, https://doi.org/10.1371/journal.pone.0166726, 2016.

Kendon, E. J., Ban, N., Roberts, N. M., Fowler, H. J., Roberts, M. J., Chan, S. C., Evans, J. P., Fosser, G., and Wilkinson, J. M.: Do convection-permitting regional climate models improve projections of future precipitation change?, B. Am. Meteorol. Soc., 98, 79-93, https://doi.org/10.1175/BAMS-D-15-0004.1, 2017.

Knist, S., Goergen, K., and Simmer, C.: Evaluation and projected changes of precipitation statistics in convection-permitting WRF climate simulations over Central Europe, Clim. Dynam., 55, 325-341, https://doi.org/10.1007/s00382-018-4147-x, 2018.

Lafon, T., Dadson, S., Buys, G., and Prudhomme, C.: Bias correction of daily precipitation simulated by a regional climate model: A comparison of methods, Int. J. Climatol., 33, 13671381, https://doi.org/10.1002/joc.3518, 2013.

Lambeck, K., Rouby, H., Purcell, A., Sun, Y., and Sambridge, M.: Sea level and global ice volumes from the Last Glacial Maximum to the Holocene, P. Natl. Acad. Sci. USA, 111, 15 296-15303, https://doi.org/10.1073/pnas.1411762111, 2014.

Leung, L. R., Mearns, L. O., Giorgi, F., and Wilby, R. L.: Regional climate research, B. Am. Meteorol. Soc., 84, 89-95, https://doi.org/10.1175/BAMS-84-1-89, 2003.

Liu, Z., Wang, Y., Gallimore, R., Notaro, M., and Prentice, I. C.: On the cause of abrupt vegetation collapse in North Africa during the Holocene: Climate variability vs. vegetation feedback, Geophys. Res. Lett., 33, L22709, https://doi.org/10.1029/2006GL028062, 2006.

Liu, Z., Ballantyne, A. P., Poulter, B., Anderegg, W. R. L., Li, W., Bastos, A., and Ciais, P.: Precipitation thresholds regulate net carbon exchange at the continental scale, Nat. Commun., 9, 3596, https://doi.org/10.1038/s41467-018-05948-1, 2018.

Ludwig, P., Schaffernicht, E. J., Shao, Y., and Pinto, J. G.: Regional atmospheric circulation over Europe during the Last Glacial Maximum and its links to precipitation, J. Geophys. Res.-Atmos., 121, 2130-2145, https://doi.org/10.1002/2015JD024444, 2016.

Ludwig, P., Pinto, J. G., Raible, C. C., and Shao, Y.: Impacts of surface boundary conditions on regional climate model simulations of European climate during the Last 
Glacial Maximum, Geophys. Res. Lett., 44, 5086-5095, https://doi.org/10.1002/2017GL073622, 2017.

Luetscher, M., Boch, R., Sodemann, H., Spötl, C., Cheng, H., Edwards, R. L., Frisia, S., Hof, F., and Müller, W.: North Atlantic storm track changes during the Last Glacial Maximum recorded by Alpine speleothems, Nat. Commun., 6, 6344, https://doi.org/10.1038/ncomms7344, 2015.

Maraun, D.: Bias correction, quantile mapping, and downscaling: Revisiting the inflation issue, J. Climate, 26, 2137-2143, https://doi.org/10.1175/JCLI-D-12-00821.1, 2013.

Maraun, D.: Bias correcting climate change simulations a critical review, Curr. Clim. Change Rep., 2, 211-220, https://doi.org/10.1007/s40641-016-0050-x, 2016.

Maraun, D. and Widmann, M.: The representation of location by a regional climate model in complex terrain, Hydrol. Earth Syst. Sci., 19, 3449-3456, https://doi.org/10.5194/hess-19-3449-2015, 2015.

Maraun, D. and Widmann, M.: Cross-validation of bias-corrected climate simulations is misleading, Hydrol. Earth Syst. Sci., 22, 4867-4873, https://doi.org/10.5194/hess-22-4867-2018, $2018 \mathrm{a}$.

Maraun, D. and Widmann, M.: Statistical downscaling and bias correction for climate research, Cambridge University Press, Cambridge, UK and New York, NY, USA, 2018b.

Maraun, D., Wetterhall, F., Ireson, A. M., Chandler, R. E., Kendon, E. J., Widmann, M., Brienen, S., Rust, H. W., Sauter, T., Themeß1, M., Venema, V. K. C., Chun, K. P., Goodess, C. M., Jones, R. G., Onof, C., Vrac, M., and Thiele-Eich, I.: Precipitation downscaling under climate change: Recent developments to bridge the gap between dynamical models and the end user, Rev. Geophys., 48, RG3003, https://doi.org/10.1029/2009RG000314, 2010.

Maraun, D., Shepherd, T. G., Widmann, M., Zappa, G., Walton, D., Gutiérrez, J. M., Hagemann, S., Richter, I., Soares, P. M. M., Hall, A., and Mearns, L. O.: Towards process-informed bias correction of climate change simulations, Nat. Clim. Change, 7, 764-773, https://doi.org/10.1038/nclimate3418, 2017.

Mayewski, P. A., Rohling, E. E., Stager, J. C., Karlén, W., Maasch, K. A., Meeker, L. D., Meyerson, E. A., Gasse, F., Kreveld, S. v., Holmgren, K., Lee-Thorp, J., Rosqvist, G., Rack, F., Staubwasser, M., Schneider, R. R., and Steig, E. J.: Holocene climate variability, Quaternary Res., 62, 243-255, https://doi.org/10.1016/j.yqres.2004.07.001, 2004.

Menéndez, C. G., de Castro, M., Boulanger, J.-P., D’Onofrio, A., Sanchez, E., Sörensson, A. A., Blazquez, J., Elizalde, A., Jacob, D., Le Treut, H., Li, Z. X., Núñez, M. N., Pessacg, N., Pfeiffer, S., Rojas, M., Rolla, A., Samuelsson, P., Solman, S. A., and Teichmann, C.: Downscaling extreme month-long anomalies in southern South America, Climatic Change, 98, 379-403, https://doi.org/10.1007/s10584-009-9739-3, 2010.

Merz, N., Raible, C. C., Fischer, H., Varma, V., Prange, M., and Stocker, T. F.: Greenland accumulation and its connection to the large-scale atmospheric circulation in ERAInterim and paleoclimate simulations, Clim. Past, 9, 2433-2450, https://doi.org/10.5194/cp-9-2433-2013, 2013.

Merz, N., Born, A., Raible, C. C., Fischer, H., and Stocker, T. F.: Dependence of Eemian Greenland temperature reconstructions on the ice sheet topography, Clim. Past, 10, 1221-1238, https://doi.org/10.5194/cp-10-1221-2014, 2014a.
Merz, N., Gfeller, G., Born, A., Raible, C. C., Stocker, T. F., and Fischer, H.: Influence of ice sheet topography on Greenland precipitation during the Eemian interglacial, J. Geophys. Res.-Atmos., 119, 10,749-10,768, https://doi.org/10.1002/2014JD021940, 2014b.

Merz, N., Raible, C. C., and Woollings, T.: North Atlantic Eddy-Driven jet in interglacial and glacial winter climates, J. Climate, 28, 3977-3997, https://doi.org/10.1175/JCLI-D-14$00525.1,2015$.

Messmer, M., Gómez-Navarro, J. J., and Raible, C. C.: Sensitivity experiments on the response of $\mathrm{Vb}$ cyclones to sea surface temperature and soil moisture changes, Earth Syst. Dynam., 8, 477-493, https://doi.org/10.5194/esd-8-477-2017, 2017.

MeteoSwiss: Documentation of MeteoSwiss gridded data product, daily precipitation: RhiresD, available at: http://www.meteoschweiz.admin.ch/content/ dam/meteoswiss/de/service-und-publikationen/produkt/ raeumliche-daten-niederschlag/doc/ProdDoc_RhiresD.pdf (last access: 12 October 2020), 2013.

Mitchell, D., Davini, P., Harvey, B., Massey, N., Haustein, K., Woollings, T., Jones, R., Otto, F., Guillod, B., Sparrow, S., Wallom, D., and Allen, M.: Assessing mid-latitude dynamics in extreme event attribution systems, Clim. Dynam., 48, 3889-3901, https://doi.org/10.1007/s00382-016-3308-z, 2017.

Moss, R. H., Edmonds, J. A., Hibbard, K. A., Manning, M. R., Rose, S. K., van Vuuren, D. P., Carter, T. R., Emori, S., Kainuma, M., Kram, T., Meehl, G. A., Mitchell, J. F. B., Nakicenovic, N., Riahi, K., Smith, S. J., Stouffer, R. J., Thomson, A. M., Weyant, J. P., and Wilbanks, T. J.: The next generation of scenarios for climate change research and assessment, Nature, 463, 747-756, https://doi.org/10.1038/nature08823, 2010.

Murphy, J.: An evaluation of statistical and dynamical techniques for downscaling local climate, J. Climate, 12, 2256-2284, https://doi.org/10.1175/15200442(1999)012<2256:AEOSAD>2.0.CO;2, 1999.

Neale, R. B., Richter, J. H., Conley, A. J., Park, S., Lauritzen, P. H., Gettelman, A., Rasch, P. J., and Vavrus, J.: Description of the NCAR community atmosphere model (CAM4), National Center for Atmospheric Research Tech. Rep. NCAR/TN+ STR, available at: http://www.cesm.ucar.edu/models/ccsm4.0/ cam/docs/description/cam4_desc.pdf (last access: 12 October 2020), 2010.

Nešpor, V. and Sevruk, B.: Estimation of wind-induced error of rainfall gauge measurements using a numerical simulation, J. Atmos. Ocean. Tech., 16, 450-464, https://doi.org/10.1175/15200426(1999)016<0450:EOWIEO>2.0.CO;2, 1999.

Oleson, W., Lawrence, M., Bonan, B., Flanner, G., Kluzek, E., Lawrence, J., Levis, S., Swenson, C., Thornton, E., Dai, A., Decker, M., Dickinson, R., Feddema, J., Heald, L., Hoffman, F., Lamarque, J.-F., Mahowald, N., Niu, G.-Y., Qian, T., Randerson, J., Running, S., Sakaguchi, K., Slater, A., Stockli, R., Wang, A., Yang, Z.-L., Zeng, X., and Zeng, X.: Technical description of version 4.0 of the community land model (CLM), NCAR Technical Note NCAR/TN-478+STR, National Center for Atmospheric Research, National Center for Atmospheric Research, Boulder, CO, ISSN 2153-2397, available at: http://www.cesm.ucar.edu/ models/cesm1.0/clm/CLM4_Tech_Note.pdf (last access: 12 October 2020), 2010. 
Otto-Bliesner, B. L., Brady, E. C., Clauzet, G., Tomas, R., Levis, S., and Kothavala, Z.: Last Glacial Maximum and Holocene Climate in CCSM3, J. Climate, 19, 2526-2544, https://doi.org/10.1175/JCLI3748.1, 2006.

Peltier, W. R. and Fairbanks, R. G.: Global glacial ice volume and Last Glacial Maximum duration from an extended Barbados sea level record, Quaternary Sci. Rev., 25, 3322-3337, https://doi.org/10.1016/j.quascirev.2006.04.010, 2006.

Piani, C., Haerter, J. O., and Coppola, E.: Statistical bias correction for daily precipitation in regional climate models over Europe, Theor. Appl. Climatol., 99, 187-192, https://doi.org/10.1007/s00704-009-0134-9, 2010a.

Piani, C., Weedon, G. P., Best, M., Gomes, S. M., Viterbo, P., Hagemann, S., and Haerter, J. O.: Statistical bias correction of global simulated daily precipitation and temperature for the application of hydrological models, J. Hydrol., 395, 199-215, https://doi.org/10.1016/j.jhydrol.2010.10.024, 2010b.

Pinto, J. G. and Ludwig, P.: Extratropical cyclones over the North Atlantic and western Europe during the Last Glacial Maximum and implications for proxy interpretation, Clim. Past, 16, 611626, https://doi.org/10.5194/cp-16-611-2020, 2020.

Prein, A. F., Langhans, W., Fosser, G., Ferrone, A., Ban, N., Goergen, K., Keller, M., Tölle, M., Gutjahr, O., Feser, F., Brisson, E., Kollet, S., Schmidli, J., Lipzig, N. P. M. v., and Leung, R.: A review on regional convection-permitting climate modeling: Demonstrations, prospects, and challenges, Rev. Geophys., 53, 323-361, https://doi.org/10.1002/2014RG000475, 2015.

Raible, C. C., Stocker, T. F., Yoshimori, M., Renold, M., Beyerle, U., Casty, C., and Luterbacher, J.: Northern hemispheric trends of pressure indices and atmospheric circulation patterns in observations, reconstructions, and coupled GCM simulations, J. Climate, 18, 3968-3982, https://doi.org/10.1175/JCLI3511.1, 2005.

Raible, C. C., Lehner, F., González-Rouco, J. F., and FernándezDonado, L.: Changing correlation structures of the Northern Hemisphere atmospheric circulation from 1000 to 2100 AD, Clim. Past, 10, 537-550, https://doi.org/10.5194/cp-10-5372014, 2014.

Raible, C. C., Brönnimann, S., Auchmann, R., Brohan, P., Frölicher, T. L., Graf, H.-F., Jones, P., Luterbacher, J., Muthers, S., Neukom, R., Robock, A., Self, S., Sudrajat, A., Timmreck, C., and Wegmann, M.: Tambora 1815 as a test case for high impact volcanic eruptions: Earth system effects, Wiley Interdiscip. Rev. Clim. Change, 7, 569-589, https://doi.org/10.1002/wcc.407, 2016.

Rajczak, J. and Schär, C.: Projections of future precipitation extremes over Europe: A multimodel assessment of climate simulations, J. Geophys. Res.-Atmos., 122, 10773-10 800, https://doi.org/10.1002/2017JD027176, 2017.

Rajczak, J., Kotlarski, S., and Schär, C.: Does quantile mapping of simulated precipitation correct for biases in transition probabilities and spell lengths?, J. Climate, 29, 1605-1615, https://doi.org/10.1175/JCLI-D-15-0162.1, 2016.

Richter, D.: Ergebnisse methodischer untersuchungen zur korrektur des systematischen messfehlers des hellmannniederschlagsmessers, Deutscher Wetterdienst, Offenbach, 1995.

Rougier, J., Sexton, D. M. H., Murphy, J. M., and Stainforth, D.: Analyzing the climate sensitivity of the HadSM3 climate model using ensembles from different but related experiments, J. Cli- mate, 22, 3540-3557, https://doi.org/10.1175/2008JCLI2533.1, 2009.

RStudio Team: RStudio: Integrated Development Environment for R, RStudio, Inc., Boston, MA, available at: http://www.rstudio. com/ (last access: 12 October 2020), 2015.

Schmidli, J., Schmutz, C., Frei, C., Wanner, H., and Schär, C.: Mesoscale precipitation variability in the region of the European Alps during the 20th century, Int. J. Climatol., 22, 1049-1074, https://doi.org/10.1002/joc.769, 2002.

Schmidli, J., Frei, C., and Vidale, P. L.: Downscaling from GCM precipitation: A benchmark for dynamical and statistical downscaling methods, Int. J. Climatol., 26, 679-689, https://doi.org/10.1002/joc.1287, 2006.

Schulzweida, U.: CDO User Guide (Version 1.9.6), Zenodo, https://doi.org/10.5281/zenodo.2558193, 2019.

Schwarb, M., Daly, C., Frei, C., and Schär, C.: Mean annual and seasonal precipitation in the European Alps 1971-1990, Hydrological Atlas of Switzerland, Landeshydrologie und Geologie, Bern, Switzerland, 2001.

Seguinot, J., Khroulev, C., Rogozhina, I., Stroeven, A. P., and Zhang, Q.: The effect of climate forcing on numerical simulations of the Cordilleran ice sheet at the Last Glacial Maximum, The Cryosphere, 8, 1087-1103, https://doi.org/10.5194/tc8-1087-2014, 2014.

Seguinot, J., Ivy-Ochs, S., Jouvet, G., Huss, M., Funk, M., and Preusser, F.: Modelling last glacial cycle ice dynamics in the Alps, The Cryosphere, 12, 3265-3285, https://doi.org/10.5194/tc-12-3265-2018, 2018.

Sevruk, B.: Systematischer Niederschlagsmessfehler in der Schweiz, Der Niederschlag in der Schweiz. Beiträge zur Geologie der Schweiz - Hydrologie, 31, 65-75, 1985.

Shepard, D. S.: Computer mapping: The SYMAP interpolation algorithm, in: Spatial Statistics and Models, Theory and Decision Library, pp. 133-145, Springer, Dordrecht, https://doi.org/10.1007/978-94-017-3048-8_7, 1984.

Skamarock, W. C. and Klemp, J. B.: A time-split nonhydrostatic atmospheric model for weather research and forecasting applications, J. Comput. Physics, 227, 3465-3485, https://doi.org/10.1016/j.jcp.2007.01.037, 2008.

Skamarock, W. C., Klemp, J. B., Dudhia, J., Gill, D. O., Barker, D. M., Wang, W., and Powers, J. G.: A description of the advanced research WRF version 2, available at: https://www2.mmm.ucar. edu/wrf/users/index.html (last access: 12 October 2020), National center for atmospheric research, Boulder, CO, USA, 2005.

Solman, S. A., Nuñez, M. N., and Cabré, M. F.: Regional climate change experiments over southern South America. I: Present climate, Clim. Dynam., 30, 533-552, https://doi.org/10.1007/s00382-007-0304-3, 2008.

Stocker, T., Plattner, G.-K., Tignor, M., Allen, S., Boschung, J., Nauels, A., Xia, Y., Bex, V., and Midgley, P., eds.: Climate change 2013: The physical science basis. Contribution of working group I to the fifth assessment report of IPCC the Intergovernmental Panel on Climate Change, Cambridge University Press, Cambridge, United Kingdom and New York, NY, USA, https://doi.org/10.1017/CBO9781107415324, 2013.

Su, F., Duan, X., Chen, D., Hao, Z., and Cuo, L.: Evaluation of the global climate models in the CMIP5 over the Tibetan Plateau, J. Climate, 26, 3187-3208, https://doi.org/10.1175/JCLI-D-12$00321.1,2012$. 
Sun, F., Roderick, M. L., Lim, W. H., and Farquhar, G. D.: Hydroclimatic projections for the Murray-Darling Basin based on an ensemble derived from Intergovernmental Panel on Climate Change AR4 climate models, Water Resour. Res., 47, W00G02, https://doi.org/10.1029/2010WR009829, 2011.

Teng, J., Potter, N. J., Chiew, F. H. S., Zhang, L., Wang, B., Vaze, J., and Evans, J. P.: How does bias correction of regional climate model precipitation affect modelled runoff?, Hydrol. Earth Syst. Sci., 19, 711-728, https://doi.org/10.5194/hess-19711-2015, 2015.

Teutschbein, C. and Seibert, J.: Bias correction of regional climate model simulations for hydrological climate-change impact studies: Review and evaluation of different methods, J. Hydrol., 456457, 12-29, https://doi.org/10.1016/j.jhydrol.2012.05.052, 2012.

Teutschbein, C. and Seibert, J.: Is bias correction of regional climate model (RCM) simulations possible for nonstationary conditions?, Hydrol. Earth Syst. Sci., 17, 5061-5077, https://doi.org/10.5194/hess-17-5061-2013, 2013.

Themessl, M. J., Gobiet, A., and Leuprecht, A.: Empiricalstatistical downscaling and error correction of daily precipitation from regional climate models, Int. J. Climatol., 31, 1530-1544, https://doi.org/10.1002/joc.2168, 2011.

Themessl, M. J., Gobiet, A., and Heinrich, G.: Empirical-statistical downscaling and error correction of regional climate models and its impact on the climate change signal, Climatic Change, 112, 449-468, https://doi.org/10.1007/s10584-011-0224-4, 2012.

UCAR/NCAR/CISL/TDD: The NCAR Command Language (Version 6.6.2) [Software], https://doi.org/10.5065/D6WD3XH5, 2019.

Ungersböck, M., Auer, I., Rubel, F., Schöner, W., and Skomorowski, P.: Zur Korrektur des systematischen Fehlers bei der Niederschlagsmessung: Anwendung des Verfahrens für die ÖKLIM Karten, 5, 2001.

Velasquez, P., Messmer, M., and Raible, C. C.: Code and Dataset, Zenodo, https://doi.org/10.5281/zenodo.4009101, 2019.

Velasquez, P., Kaplan, J. O., Messmer, M., Ludwig, P., and Raible, C. C.: Iterative asynchronous modeling of surface conditions over Europe during LGM, Quaternary Sci. Rev., in preparation, 2020.

Wang, Z., Wen, X., Lei, X., Tan, Q., Fang, G., and Zhang, X.: Effects of different statistical distribution and threshold criteria in extreme precipitation modelling over global land areas, Int. J. Climatol., 40, 1838-1850, https://doi.org/10.1002/joc.6305, 2020.

Warrach-Sagi, K., Schwitalla, T., Wulfmeyer, V., and Bauer, H.-S.: Evaluation of a climate simulation in Europe based on the WRFNOAH model system: Precipitation in Germany, Clim. Dynam., 41, 755-774, https://doi.org/10.1007/s00382-013-1727-7, 2013.
Wilcke, R. A. I., Mendlik, T., and Gobiet, A.: Multi-variable error correction of regional climate models, Climatic Change, 120, 871-887, https://doi.org/10.1007/s10584-013-0845-x, 2013.

Wilks, D. S.: Statistical methods in the atmospheric sciences, Academic Press, 2011.

Wren, C. D. and Burke, A.: Habitat suitability and the genetic structure of human populations during the Last Glacial Maximum (LGM) in Western Europe, PLoS One, 14, e0217 996, https://doi.org/10.1371/journal.pone.0217996, 2019.

Wu, H., Guiot, J., Brewer, S., and Guo, Z.: Climatic changes in Eurasia and Africa at the last glacial maximum and mid-Holocene: reconstruction from pollen data using inverse vegetation modelling, Clim. Dynam., 29, 211-229, https://doi.org/10.1007/s00382-007-0231-3, 2007.

$\mathrm{Xu}, \mathrm{C} .-\mathrm{y} .:$ Modelling the effects of climate change on water resources in central sweden, Water Resources Management, 14, 177-189, https://doi.org/10.1023/A:1026502114663, 2000.

Xu, C.-y., Widén, E., and Halldin, S.: Modelling hydrological consequences of climate change - Progress and challenges, Advances in Atmospheric Sciences, 22, 789-797, https://doi.org/10.1007/BF02918679, 2005.

Yang, B., Qian, Y., Lin, G., Leung, L. R., Rasch, P. J., Zhang, G. J., McFarlane, S. A., Zhao, C., Zhang, Y., Wang, H., Wang, M., and Liu, X.: Uncertainty quantification and parameter tuning in the CAM5 Zhang-McFarlane convection scheme and impact of improved convection on the global circulation and climate, J. Geophys. Res.-Atmos., 118, 395-415, https://doi.org/10.1029/2012JD018213, 2013.

Yang, W., Andréasson, J., Graham, L. P., Olsson, J., Rosberg, J., and Wetterhall, F.: Distribution-based scaling to improve usability of regional climate model projections for hydrological climate change impacts studies, Hydrology Research, 41, 211-229, https://doi.org/10.2166/nh.2010.004, 2010.

Yokoyama, Y., Lambeck, K., De Deckker, P., Johnston, P., and Fifield, L. K.: Timing of the Last Glacial Maximum from observed sea-level minima, Nature, 406, 713-716, https://doi.org/10.1038/35021035, 2000.

Zhang, G. J. and McFarlane, N. A.: Sensitivity of climate simulations to the parameterization of cumulus convection in the Canadian climate centre general circulation model, Atmosphere-Ocean, 33, 407-446, https://doi.org/10.1080/07055900.1995.9649539, 1995.

Zhao, Y., Liu, Y., Guo, Z., Fang, K., Li, Q., and Cao, X.: Abrupt vegetation shifts caused by gradual climate changes in central Asia during the Holocene, Science China Earth Sciences, 60, 13171327, https://doi.org/10.1007/s11430-017-9047-7, 2017. 